

\title{
LA MORALIZACIÓN DE LA VIDA PÚBLICA EN LOS REINOS BÁRBAROS. EL PROYECTO DE TEODORICO Y CASIODORO
}

POR

\author{
ANDRES BARCALA
}

C.E.H., CSIC

\section{RESUMEN}

En los primeros reinos bárbaros de Occidente surgieron antiguos funcionarios imperiales o clérigos cultos de mentalidad romana, que intentaron abordar las principales cuestiones planteadas por la nueva convivencia; hicieron también un notable esfuerzo por racionalizar y moralizar la vida pública y el ejercicio del poder. Uno de ellos fue Casiodoro, en el reino ostrogodo de Teodorico. Su ambicioso y efímero proyecto estuvo fundamentalmente encaminado a eliminar de la vida pública la violencia y la rapiña. Ambas aparecían como males estructurales y personales de los nuevos pueblos y había que combatirlas también con estructuras y comportamientos: implantar algunas instituciones civiles del imperio, adaptar las leyes y costumbres romanas, unificar Italia. A una sociedad eminentemente guerrera se le propone como bien primordial la paz; para lograrla con otros pueblos está la negociación, una adecuada política matrimonial y la clemencia con los enemigos; para lograrla en el interior es imprescindible la justicia y la equidad de los gobernantes en la aplicación de unas leyes claras, eficaces, justas y comunes a todos (iura publica). Para evitar la rapiña y los expolios, Casiodoro propone restaurar una fiscalidad equitativa, que proporcione los ingresos necesarios al Estado, sin oprimir a los ciudadanos. Estos, en sus relaciones, se regirán también por normas de justicia y equidad que garanticen la seguridad de sus vidas y haciendas.

\section{ABSTRACT}

In the first barbarian kingdoms of Occident appeared ancient imperial officials or roman education clerks who attempted to undertake the main questions which the new cohabitation raised. They did also a notable effort to rationalize 


\begin{abstract}
and moralize public life and the exercise of power. One them was Casiodoro, in the Teodorico's Ostrogothic kingdom. His ambitious and short-lived project was basically directed to eliminate violence and the robbery of the public life. Both appeared like structural and personal evils of the new people and had to be faced with strictures and behaviors as well: by the introduction of some civil institutions of the empire, the adoption of laws and Roman way of life, and the unification of Italy. To an eminently warlike society peace is proposed as a fundamental good. To achieve it with another nations there is agreement, an adequate matrimonial politics and mercy with the enemy; to achieve it inside there is justice and equity of the ruler in the application of a few clair, efficient and common laws (iura publica). For avoiding robbery and expoliation, Casiodoro proposes to restore an equitable fiscality that provides the necessary earnings to the State, without squeezing he citizenry. They, in their relations, will be ruled also by norms of justice and equity that will guarantee the security of lifes and properties.
\end{abstract}

Los primeros reinos surgidos en el ámbito mediterráneo tras la desmembración del Imperio de Occidente fueron obra de los pueblos germanos. No todos se implantaron en las mismas condiciones, pero la mayoría de ellos tuvieron unos inicios vacilantes, una vida precaria y un final abrupto, dejando poca huella en los siglos medievales; sólo el reino visigodo y el longobardo alcanzaron una historia de más de dos siglos, crearon instituciones estables y acabaron siendo los más importantes antes de Carlomagno. En todos ellos, por breve que fuera su existencia, se introdujo con los nuevos asentarmientos un conjunto de costumbres y de ideas sobre la sociedad y su organización, sobre el poder y su ejercicio, que chocaba con la civilitas y el ordo romanos, a los que acabarían modificando y sustituyendo en buena medida. En el choque entre romanos y germanos, las transformaciones y las evoluciones predominaron sobre las destrucciones; en todas partes hubo compromisos, más o menos logrados, y síntesis parciales de elementos contrapuestos.

Esa simbiosis progresiva estuvo fuertemente marcada, cuando no dirigida, por antiguos funcionarios imperiales y por un clero culto de mentalidad romana. Ellos eran quienes poseían, casi en exclusiva, los medios del saber y disponían de los conocimientos que permitían abordar de modo más teórico las principales cuestiones planteadas por el nuevo orden y convivencia; ellos podían también pensar por escrito y plasmar sus ideas y propuestas en obras de diversa naturaleza. Pero el interés primordial que los guiaba fue didáctico y aun catequético; las cuestiones propiamente «políticas» no fueron generalmente abordadas de modo directo y menos aún sistemático hasta bien entrada la Edad Media. No han sido escasos los escritores de todos los tiempos que han intentado comprender la sociedad en que vivían, reconstruir sus historia o describir su situación. Algunos de ellos han ido más lejos: han pretendido también escudriñar las condiciones que hacen posible la convivencia y han plas-

Proyeccion internacional de la iglesia hispana

Hispania Sacra 51 (1999) 
mado en los escritos más variados su esfuerzo por racionalizar y moralizar la vida pública. No pretenden hacer teoría del Estado, sino dar unas pautas, que consideran necesarias para el correcto ejercicio del poder.

Esa necesidad se hizo sentir, de modo quizá más acuciante, tras el largo período de invasiones y de primeros asentamientos bárbaros. En el reino suevo hispano, en el visigodo, en el vándalo de Africa, en el franco, en el ostrogodo aparecen personalidades de relevancia y prestigio, que incluso asesoran a los gobernantes en su tarea. Algunos de ellos se limitaron, al parecer, a denunciar lo que consideraban abusos en el ejercicio del poder, a la manera de los profetas veterotestamentarios; otros, por el contrario, creyeron necesario también proponer medios y normas de conducta, que hicieran más «civilizada» la convivencia y eliminaran las principales lacras que creían detectar en sus respectivos reinos.

En el presente artículo me voy a ceñir al proyecto elaborado por Casiodoro y Teodorico para el reino ostrogodo de Italia: es el primero de que nos ha llegado una amplia noticia, gracias a la documentación de la cancillería regia, compuesta por cartas, edictos y fórmulas curiales, redactadas por el propio Casiodoro durante varias décadas, a partir del año 507. El proyecto fue efímero, pero hoy podría tildarse de ambicioso. Tiene la peculiaridad de inspirarse en lo que había sido el imperio romano de Occidente en sus momentos de esplendor y era todavía, en parte, el de Oriente. Se elabora de modo práctico, al hilo de los acontecimientos y las necesidades para solucionar el problema de la convivencia pacífica y ordenada de los pueblos bárbaros entre sí y con los romanos; pero aspira a transformar las costumbres de aquéllos, a moralizarlas mediante unas leyes justas, a racionalizarlas mediante mecanismos eficaces de un ejercicio del poder beneficioso, que garantice a los súbditos seguridad y bienestar y pueda servir de modelo a otros reinos.

\section{LA VIOLENCIA Y LA RAPIÑA}

Entre los diversos aspectos concernientes a las invasiones bárbaras de los siglos V-VI y a los reinos surgidos de ellas, interesa ahora destacar dos, que son precisamente los que más han puesto de relieve las fuentes que nos han llegado, tanto históricas como literarias, y los que fundamentalmente confirman otros testimonios, especialmente arqueológicos. Se trata de la violencia y la rapiña que acompañaron a las invasiones y pervivieron durante toda la Alta Edad media. No son, desde luego, las únicas calamidades de que nos hablan 
las fuentes; pero sí son éstas precisamente las que revistieron un carácter más llamativo y alarmante para los escritores y cronistas de la época ${ }^{1}$.

1.- S. Jerónimo, hombre profundamente romano, no fue testigo presencial de los acontecimientos, pero sí fue uno de los escritores mejor informados y más leídos de su tiempo. En su retito de Jerusalén, recibía una abundante correspondencia de todo el Imperio, en la que se le preguntaba por las cuestiones más variadas y se le daban noticias de numerosos acontecimientos. Muchas de ellas eran difundidas también por él a sus corresponsales o a quienes acudían a visitarle y trabajar a su lado ${ }^{2}$. Desde el primer momento había tenido conocimiento de la invasión de las provincias orientales del Imperio: «me horroriza -escribe- enumerar todas las calamidades de nuestro tiempo; hace ya más de veinte años que se derrama diariamente sangre romana; Escitia, Tracia, Macedonia, Dardania, Doria, Tesalia, Acaya, Epiro, Dalmacia y ambas Pannonias están en poder de los godos, sármatas, quades, alanos, hunos, vándalos, marcomanos, que las saquean, las devastan y las destrozan ${ }^{3}$. Pero igual conmoción le había causado la invasión de las provincias occidentales, especialmente de las Galias, joya de esa parte del Imperio: «pueblos innumerables y extremadamente violentos (ferocissimi) han invadido las Galias; todo lo que hay entre los Alpes y los Pirineos, entre el Océano y el Rhin, ha sido devastado por los quades, los vándalos, los sármatas, los alanos, los gipedes, los hérulos, los sajones, los burgundios, los alamanes y, joh triste República!, los panonios...; Maguncia, en tiempos ciudad noble, ha sido conquistada y arrasada y sus habitantes despedazados (trucidati) por miles en las iglesias; los pobladores de

\footnotetext{
1 Prescindiendo de fenómenos atmosféricos o astrales (terremotos, inundaciones, eclipses, etc.), que suelen ser interpretados como presagios de nuevos males, las fuentes mencionan otras calamidades, secuela inevitable de las devastaciones, deportaciones y matanzas: la peste, el hambre, etc. Baste sólo el testimonio de Hidacio: «debacchantibus per Hispanias barbaris et saeviente nihilominus pestilentiae malo... fames dira grassatur; bestiae occisorum gladio fame pestilentia cadaveribus adsuetae quosque hominum fortiores interimunt» (Chron., 48; Th. MOMMSEN, Monumenta Germaniae Historica $=M G H$, Auct. Ant.,XI,17-18). Hidacio, como harán también otros autores, se refiere a cuatro plagas («ferri, famis, pestilentiae, bestianum») anunciadas por los profetas en el AT; pero, en realidad, las principales secuelas fueron el hambre, por la abundante pérdida de recursos, y la peste por la putrefacción de los numerosos cadáveres que quedaban sin enterrar: «Huni, qui Italiam praedabantur, aliquantis etiam civitativus inruptis, divinitus partim fame, partim morbo quodam plagis caelestibus feriuntur» (HIDAD., Chron., 154; MGH, Auct.Ant., XI, 26-27).

2 Basta hojear su correspondencia, que ocupa un grueso volumen de la Patrologia Latina de Migne.

3 JeRON., Ep. 60,16, ad Heliodorum (P. Migne, Patrologia Latina = PL 22,600): «horret animus temporum nostrorum ruinas persequi; viginti et eo amplius anni sunt quod inter Constantinopolim et Alpes Julias quottidie romanus sanguis effuditur; Scytiam, Thraciam, Macedoniam, Dardaniam, Daciam, Thessaliam, Achaiam, Epiros, Dalmatiam, cunctasque Pannonias Gothus, Sarmata, Quadus, Alanus, Hunni, Wandali, Marcomani vastant, trahunt, rapiunt». La carta es del año 396.
}

Proyección internacional de la iglesia hispana Hispania Sacra 51 (1999) 
Worms han sido aniquilados por un largo asedio; los de la poderosa Reims, los de Amberes, los de Arras y los más periféricos de Boulogne, Tournai, Espira y Estrasburgo han sido deportados a Germania; las provincias de Aquitania, la Novempopulonia, la Lugdunense y la Narbonense han sido completamente arrasadas, excepto unas pocas ciudades; y aun éstas son desvastadas exteriormente por las armas e interiormente por el hambre; no puedo mencionar sin que me salten las lágrimas la ciudad de Toulouse, que nunca había sido conquistada hasta ahora...» ${ }^{4}$. Para S. Jerónimo, la situación del Imperio era tan calamitosa que, «según las miserias de este tiempo y las matanzas que se producen por todas partes, es bastante rico quien no tiene falta de pan y demasiado poderoso quien no es forzado a la esclavitud» ${ }^{5}$.

España no iba a quedar al margen de esas calamidades. Mientras las Galias eran devastadas, el temor se extendía por la Península y crecía la ansiedad con las noticias que traían a ella los que habían podido huir pasando los Pirineos o el Mediterráneo. Una catástrofe similar parecía inevitable y cercana, según los observadores más perspicaces ${ }^{6}$. Algunos testigos presenciales nos ofrecen también, pese a su brevedad, datos suficientemente elocuentes de la crudeza de las invasiones. Orosio, que había tenido que huir de España para librarse, como él mismo dice, «de las piedras y las flechas», escribía desde Africa, donde había ido a refugiarse cerca de S. Agustín: «han sido invadidas las Españas y han padecido matanzas y devastaciones»; «los germanos son dueños de una España arrasada», «de modo que, al presente, tenemos conocimiento cada día, por sucesivos mensajeros dignos de crédito, que en las Españas se producen guerras entre los pueblos y que se llevan a cabo matanzas de un pueblo bárbaro o de otro», y «todavía se ven por diversas provincias, entre las ruinas de las grandes ciudades, barrios pequeños y pobres que conservan el vestigio de sus

4 ID., Ep. 123,16-17 ad Ageruchiam (PL 22,1057-8): «innumerabilis et ferocissimae nationes universas Gallias occuparunt. Quidquid inter Alpes et Pyrenaeum est, quod Oceano et Rhemo includitur, Quadus, Wandalus, Sarmata, Halani, Gipetes, Heruli, Saxones, Burgundiones, Alamani, et, o lugenda Respublica!, Pannoni vastarunt...; Moguntiacum, nobilis quondam civitas, capta atque subversa est, et in ecclesia multa hominun milia trucidata; Vangiones longa obsidione deleti; Remorum urbs praepotens, Ambiani, Attrebates, extremique hominum Morini, Tornacus, Nemetiae, Argentoratus translatae in Germaniam; Aquitaniae, Novernque populorum, Lugdunensis, et Narbonensis provinciae, praeter paucas urbes, populata sunt cuncta; quas et ipsas foris gladius, intus vastat fames; non possum absque lacrymis Tolosae facere mentionem, quae ut hucusque non rueret...»

5 ID., Ep. 125,20 ad Rusticum (PL 22,1085): «caeterum juxta miserias hujus temporis, et ubique gladios saevientes, satis dives est, qui pane non indiget; nimirum potens est, qui servire non cogitur».

6 El propio S. Jerónimo ya lo había previsto por lo que le decían sus informadores: «Ipsae Hispaniae jam jamque periturae, quottidie contremiscunt, recordantes irruptionis Cimbricae, et quidquid alii semel passi sunt illae semper timore patiuntur» (Ep. 123,16 ad Ageruchiam; PL 22,1058). 
nombres y de esas calamidades» ${ }^{7}$. En otras, ni siquiera eso: sólo ruinas. También Hidacio, gallego de nacimiento y testigo presencial, es igualmente explícito en su brevedad: «los bárbaros -dice- que habían penetrado en las Españas se dan al pillaje y la matanza sin piedad»-; «en sus correrías,.. el tiránico recaudador de impuestos y los soldados acaban con las riquezas y los aprovisionamientos de las ciudades»; «los vándalos entregan al pillaje las islas Baleares y, después de destruir Cartagena y Sevilla y de saquear España, invaden Mauritania» ${ }^{8}$. El propio S. Agustín, contemporáneo de los acontecimientos y muy cercano a la Península, nos habla de que en ella ha habido fugas precipitadas, matanzas, asedios, cautividad y deportaciones?.

Se ha discutido mucho sobre la exactitud de éstas o de otras noticias similares y no son raros los historiadores que creen que se trata de excesos retóricos. Es cierto que los escritores del Bajo Imperio exageraron las calamidades de las invasiones: unos para acentuar mejor su carácter de «castigo divino» y otros para poner más de relieve el contraste ente el «orden» romano y la «barbarie» germana, marcando así la contraposición Romania-Gothia ${ }^{10}$. Unos y otros escribieron, sin duda, con intereses propios. Pero nadie se ha atrevido a negar que existieron, en una proporción y extensión no conocidas hasta entonces, matanzas, destrucciones y expolios. Hay que tener en cuenta además otros hechos. S. Jerónimo, que dio en cierta medida la pauta a otros escritores, era un intelectual de espíritu preciso y poco dado a fantasías, como muestran sus

7 OROS10, Historiarum adversus paganos, VII,41,2 (CSEL 5,552-3): «inruptae sunt Hispaniae, caedes vastationesque passae sunt»; «Germani ulteriores abrasa potiuntur Hispania» (ibid., VII,22,8); «nunc Galliarum Hispaniarumque provinciae praemuntur» (ibid., VII 38,3); itaque nunc cottidie apud Hispanias geri bella gentium et agi strages ex alterutro barbarorum crebris certisque nuntiís discimus» (ibid., VII,43,15); «extant adhunc per diversas provincias, in magnarum urbium ruinis, parvae et pauperes sedes, signa miseriarum et nominun indicia servantes» (ibid., VII,22,8). Orosio escribe esto hacia el año 418 .

8 HIDACIO, Chronicon, 46 (MGH, Auct. Ant., XI, 17): «Barbari qui in Hispanias ingressi fuerant caede depraedantur bostili»; «debacchantibus per Hispanias barbaris..., opes et conditam in urbibus substantiam tyrannicus exactor, et miles exhaurit» (ibid., 48; MGH, Auct. Ant., XI,17); «Vandali Balearicas insulas depraedantur, deinde Carthagine Spartaria et Hispali eversa, et Hispaniis depraedatis, Mauritaniam invadunt» (ibid., 86; MGH, Auct.Ant., $\mathrm{XI}, 21$ ).

9 Ep. 228,15 (PL 33,1015): «plebibus partim fuga lapsis, partim peremptis, partim obsidione consumptis, partim captivitate dispersis...».

10 Sobre la oposición Romania-Gothia cfr. A. BARCALA, Historia de la teoría politica. Edad Media (Madrid 1990) pp. 222 ss. y bibliografía allí citada, Que yo sepa, el primero que llamó la atención sobre las posibles exageraciones de las fuentes fue H. KLEINSCHMIDT, Über die sogenantes Vandalismus (Torgau 1875), prol.; recogió su opinión F. MIEDEL, "Vardalismus», Zeitschrift der allgemeine deustschen Sprachvereins, 20 (1905) $37 \mathrm{ss}$. y a ellos les han seguido otros. Sin embargo, hay que decir que el hecho de que los pueblos germanos acabasen asentándose en diversas provincias del Imperio o que no pretendieran inicialmente acabar con él no es argumento suficiente para invalidar de modo general las noticias dadas por las fuentes sobre matanzas y rapiñas.

Proyección internacional de la iglesia hispana

Hispania Sacra 51 (1999) 
obras marcadamente filológicas; como él mismo dice, no amplió sino que redujo y calló otras muchas calamidades por prudenciall. Tanto él como otros autores eran gentes acostumbradas al espectáculo frecuente de la violencia y la rapiña y no se escandalizaban fácilmente de ellas, aunque las criticasen; no eran precisamente temperamentos apocados, que ignorasen la realidad del mundo en que vivían y del que procuraban estar bien informados: habían leído en otros autores, o conocido ellos mismos, ejemplos insignes de crueldad y codicia, que podían servirles de punto de comparación ${ }^{12}$. Sobre todo, en el frío y escueto lenguaje de la crónica, la mayoría de ellos manifestaron su desolación y sorpresa ante acontecimientos que consideraron, en gran medida, nuevos y más atroces.

2.- La situación de las provincias del Imperio parecía calamitosa tras las invasiones; pero era, sobre todo, Roma la que daba a muchos la medida de la catástrofe y les hacía pensar que algo decisivo había cambiado. S. Jerónimo recibía la noticia del asedio de Roma por Alarico y la daba a conocer a sus amigos: «Mientras estas cosas suceden en Jerusalén -dice- me llega de Occidente la terrible noticia de que Roma está sitiada y que los ciudadanos han salvado su vida pagando un rescate; que los que han sido expoliados son nuevamente asediados, de modo que, después de perder sus bienes, perderán también sus vidas ${ }^{13}$. Como en otras ocasiones, no se iba a equivocar en la previsión de los hechos; tampoco probablemente en la interpretación de su significado. Después de describir la suerte corrida por algunos de sus amigos y conocidos, insiste en lo que le parece desprenderse de lo sucedido: «no estoy contando las calamidades de unos desdichados, sino la fragilidad de la condición

11 «Caetera taceo ne videar de Dei desperare clementia» (Ep. 123,17 ad Ageruchiam; PL 22,1058).

12 Famoso era en el siglo V el caso del conde Heracliano, del que dice S. Jerónimo: «excipitur enim ab eo quem nescias, utrum avarior an crudelior fuerit: cui nihil dulce praeter vinum, et praetium; et qui... saevissimus omnium extitit tyrannorum» (Ep. 130,7 ad Demetriadem; PL. 22,1112). Hablan también de este personaje Próspero de Aquitania, el Conde Marcelino, Orosio y otros. Precisamente Orosio, que había confeccionado pacientemente para su Historia una amplia lista de tiranos de todos tiempos, famosos por su crueldad y codicia (Hist. VII,42), consideraba inútilmente violentos muchos acontecimientos del Imperio romano, que eran vistos por otros como gestas gloriosas: «no hay que minimizar -dice- tantas guerras serviles, sociales, civiles, de esclavos fugitivos, que no produjeron ciertamente frutos, sino grandes calamidades» (ibid., $\mathrm{V}, 1,1-6$ ).

13 Ep. 127,12 ad Principiam (PL 22,1094): «dum haec aguntur in Jebus, terribilis de Occidente numor affertur, obsideri Romam et auro salutem civium redimi; spoliatosque rursum circundari, ut post substantiam, vitan quoque perderent». Como es sabido, el año 409 Alarico no tomó Roma y se contentó con recibir como rescate una ingente suma de oro y plata; pero al año siguiente, ante el rechazo de paz por parte del emperador Honorio, sitió nuevamente la ciudad, entró en ella y durante tres días lanzó sus tropas al pillaje, las destrucción y las matanzas. 
humana» ${ }^{14}$ con sus obras más eminentes y que parecían más sólidas; porque «si Roma perece, ¿quién estará a salvo?» y así «se desmorona el mundo romano» ${ }^{15}$. Visto desde la perspectiva que nos da el tiempo, el testimonio de S. Jerónimo tiene un doble valor: el de intuir que lo sucedido con Roma no era un episodio más de los muchos que habían sacudido al Imperio; y el de expresar, mejor seguramente que sus contemporáneos, el sentir más común de los romanos. En efecto, Salviano nos confirma que estaba en la conciencia de todos que el Estado romano se había agotado ya ${ }^{16}$, que el cambio producido era tan profundo como brutal y que un orden nuevo empezaba a surgir ${ }^{17}$.

Un orden nuevo que a los hombres de cultura y mentalidad «romana» les parecía desorden y barbarie. No se trataba de que en el Imperio no hubiese habido violencia y rapiñas ${ }^{18}$; pero las practicadas durante las invasiones y en los reinos que comenzaban a surgir de ellas tenían para muchos una novedad sustancial e inquietante: su amplitud y asiduidad ${ }^{19}$; no eran tanto individuales o de pequeños grupos, sino colectivas; no eran tanto coyunturales o esporádicas como fruto de una acción planificada y de una situación estructural; constituían, en cierta medida desconocida hasta entonces, una forma de organización y un modo de vida. Pese a la confusión de aquellos tiempos revueltos, esto es, al parecer, lo que presintieron algunos testigos de los acontecimientos. Desde luego, los interpretaron desde una óptica romana: los escritores de esos siglos son casi exclusivamente gentes de formación eclesiástica o miembros de la tardía burocracia civil, acostumbrados todos a las instituciones, las leyes y la cultura del Imperio; su formación había creado en ellos una serie de hábitos mentales y de supuestos compartidos, que no era necesario ni siquiera explicitar; los había imbuido, sobre todo, de la «interpretatio romana» de las costum-

${ }^{14}$ Ep. 60,16 ad Heliodorum (PL 22,600): «non calamitates miserorum, sed fragilitatem humanae conditionis narro statum...".

15 «Potentiam romanae urbis, ardens poeta describens ait: quid satis est si Roma parum est?; quod nos alio mutemus elogio: quid salvum est si Roma perit?» (Ep. 123,17 ad Ageruchiam; PL 22,1058). El poeta al que se refiere es Lucano (Pharsal. V). «Romanus orbis ruit et tamen cervix nostra erecta non flectimus» (Ep. 60,16 ad Heliodorum; PL 22,600).

16 SAlviano, De gubematione Dei, VII,9 (PL 53,136 C): «nullas esse iam rei publicae vires omnium conscientia est...».

17 lbid., VH,10 (PL 53,137 D): «...habens (Roma) praedatoris fiduciam, praeda fieret; triunphum praesumens, triunphus esset, circumdaretur, corriperetur, alligaretur, retorta tergo bracchia gereret; manus quas bellicosas putabat, vinctas videret; puerorum ac mulierum spectaculum fieret, inludentes sibi barbaros cerneret, inrisionem sexus promiscui sustineret, et qui maximum habuerat surpercilium fortis viri, mortem subiret ignavi».

18 Así lo recordaba Amiano Marcelino a sus contemporáneos, recomendándoles que leyeran ta historia de Roma para comprobarlo: «si superiores vel recens praeteritae revolvuntur aetates, tales tamque tristes rerum motus saepe contingere monstrabunt» (Hist., $\mathrm{XXXI}, 5$ ).

19 Ibid: «negant antiquitatum ignari malonm tenebris offusam aliquando fuisse rem publicam, sed falluntur malorum recentium stupore confixi».

Proyección internacional de la iglesia bispana Hispania Sacra 51 (1999) 
bres bárbaras y les había dejado un poso de incomprensión y menosprecio hacia ellas, patente incluso en autores como Orosio, Salviano y otros, que creían sinceramente en la misión providencial del pueblo godo. Pese a ello, y aun teniendo en cuenta la visión sesgada de algunas fuentes, lo que sabemos de las tribus germanas y de sus primeros asentamientos en Occidente, confirma, al menos, dos cosas: que quienes, en adelante, iban a ser protagonistas de los nuevos reinos eran pueblos de estructura y mentalidad eminentemente guerrera; y que prácticamente carecían de una economía de producción y de un sistema fiscal organizado.

3.- Existe una vieja pugna entre historiadores franceses y alemanes sobre la conveniencia de seguir considerando los acontecimientos de los siglos IV y V como invasiones bárbaras o como migraciones de pueblos germanos a Occidente. No es aquí el caso de reproducirla y, como suele pasar con las disputas de escuela, cada cual acaba encontrando lo que busca, amparado en la ambigüedad de las mutaciones históricas. Nadie pone en cuestión, sin embargo, que los nuevos establecimientos germanos distaban de responder a la vieja máxima romana «cedant arma togae», expresión de un poder civil supremo y de un ejército como mero instrumento del Estado, aunque no siempre hubiera sido así en la práctica. Los pueblos que vinieron a asentarse en las provincias occidentales del Imperio traían su propia estructura y organización, pese a que inicialmente intentaron encuadrarse en el Imperio, o incluso imitarlo ${ }^{20}$, y se sirvieron de algunos restos de sus instituciones. Pero la civilización surgida de las grandes invasiones fue durante largo tiempo una civilización de guerra y agresión ${ }^{21}$.

Los pueblos invasores constituían, en efecto, sociedades orientadas fundamentalmente a la guerra: existían en todos ellos estrechos vínculos entre la organización social, política y militar y los valores reconocidos eran, sobre todo, guerreros. Todos los hombres libres eran generalmente soldados, si no había impedimentos de edad o condición física; el caudillaje o función regia era, ante todo, la de dirigir la guerra (Heerkönigtum) y obtener la victoria; el rey era fundamentalmente (para ello se le elegía) «un director de conquistas» y la guerra un «género de vida tanto como un modo de supervivencia y de expansión» 22 . También las actividades no guerreras de la vida pública adoptaban,

20 Cfr. A. BARCALA, o.c., pp. 222 ss.

21 J.M. WALLACE-HADRILL, Early Germanic Kingship in England and on the Continent (Oxford 1971); G. DUBY, Guerriers et paysans (Paris 1973). Ambos intentan apartarse de las disputas estrictamente de escuela.

22 J. M. WALLACE-HADRILl, o.c., p. 151. 
a menudo, un aspecto militar ${ }^{23}$ y esa presencia constante quedaba reflejada incluso en la onomástica ${ }^{24}$. No tenían ejércitos profesionales y era todo el pueblo en movimiento quien se desplazaba con sus carretas, ganado, mujeres, niños y ancianos, que no sólo exigían protección, sino que dificultaban la movilidad. Por ello, para las acciones propiamente bélicas, solían dividirse en grupos, que hostigaban o saqueaban las zonas agrarias y asediaban las ciudades menos protegidas. También internamente eran los grupos quienes se encargaban de su propia defensa y seguridad, desapareciendo con ello toda distinción entre guerra privada (Faide) y guerra pública, dirigida por el rey en nombre del pueblo. En sus correrías o litigios, aceptaban una especie de rescate (Wergeld) para evitar males mayores; pero en caso contrario, a los vencidos por las armas se les despojaba de sus bienes, incluso con tortura, y se repartía el botín; los prisioneros eran frecuentemente sacrificados o reducidos a esclavitud; la violencia y el pillaje eran sólo contenidos excepcionalmente ${ }^{25}$.

Esa condición guerrera de'los pueblos invasores no dejó de existir después de establecerse algunos de ellos y constituir los primeros reinos bárbaros en Occidente. Los francos de Clodoveo (+ 511), los visigodos de Alarico II (+ $507)$, los ostrogodos de Teodorico $(+526)$ o de Vitiges $(+542)$, por no mencionar más que algunos, seguían formando sociedades eminentemente guerreras, que apenas habían conseguido prolongar algunos aspectos de la organización social y económica romana y que no habían adquirido todavía más estructuras estables que las destinadas a la conquista y dominación de otros pueblos. Sabemos por la correspondencia curial de Teodorico que éste se alegraba efusivamente y se felicitaba de que Clodoveo hubiese logrado unir a los diversos grupos francos «para lanzarlos a nuevas guerras y hubiera sometido a los alamanes, después de haber matado a sus mejores hombres» ${ }^{26}$. A Alarico II le advertía que no convenía estar mucho tiempo sin combates, "puesto que los

23 G. DUBY, o.c., p. 60. Hay casos verdaderamente llamativos: Regimunda, hija de Chilperico, fue acompañada para su boda con el rey visigodo Recaredo por 4.000 guerreros; el burgundio Bertoeldo, encargado del fisco, iba acompañado por 400 soldados en sus inspecciones; etc.

${ }^{24}$ La onomástica germana ha conservado esa huella, Baste recordar algunos nombres usuales entre nosotros: Ricardo (Rik-hard = poderoso, audaz); Armando (Heri-man = hombre de guerra), Roger (Hrot-gar $=$ lanza gloriosa), Guillermo (Wile- Helm = voluntad-casco); Gerardo (Ger-hard = lanza fuerte), Gertrudis (Gaire-trudis = seguridad de lanza), Matilde (Macht-hildis = poderosa para la guerra), etc. Pero hay muchos más.

25 J. P. BODMER, Der Krieger der Merowingerzeit und seine Welt. Eine Studie uber Kriegentum als Form der menschlichen Existenz in Frithmittelalter (Zurich 1957), passim.

26 CAsIODORO, Variae II,41 (MGH, Auct. Ant., XII,73): «gloriosa quidem vestrae virtutis affinitate gratularnur, quod genten Francorum... feliciter in nova prelia concitastis et Alamanicos populos caesis fortioribus inclinatos victrici dextera subdidistisn.

Proyeccion internacional de la iglesia hispana

Hispania Sacra 51 (1999) 
corazones de los pueblos guerreros se reblandecen con una larga paz ${ }^{27}$. Vitiges, que acabaría perdiendo Roma a manos de Belisario, pronunciaba un discurso ante su pueblo, al ser elegido rey, y decía como compendio de su vida y de su acción futura: «he aprendido a tener en estima a los hombres valientes, yo que he combatido en tantas guerras ${ }^{28}$. Y aun el propio Teodorico El Grande, que había intentado la experiencia política más seria de su tiempo, impulsado por Casiodoro y Boecio, no pudo tampoco desprenderse de su mentalidad guerrera, que acabaría llevando al fracaso su proyecto: «combatir -dice- es para los godos cosa de celebraciones más que de exhortaciones, porque para un pueblo guerrero es una alegría ponerse a prueba (en el combate); y ciertamente no rehuye el esfuerzo quien desea la gloria que es fruto del valor...; en tiempo de paz, el valor digno de alabanza permanece tapado y mientras no tiene ocasión de darse a conocer, queda oculta también toda la luz de sus méritos» ${ }^{29}$. Lo mismo podría decirse, sin duda, de otros reinos: el suevo y el visigodo en España, el vandalo en Africa, el burgundio en las Galias...

4.- Junto a la violencia en diversas formas, aun las más crueles, las fuentes que nos hablan de las invasiones y de los reinos surgidos de ellas coinciden frecuentemente en denunciar la codicia y las rapiñas de los nuevos señores de Occidente. Saqueo y rapiña son dos palabras que pueden encontrarse con frecuencia en los escritos de estos siglos. Y no sólo cuando se refieren a los primeros tiempos de las invasiones, sino también después, cuando ya se habían constituido monarquías independientes y, hasta cierto punto, organizadas. Todavía Hincmar de Reims se escandaliza a mediados del siglo IX de que la rapiña fuese una práctica corriente de los poderosos de su tiempo; y peor aún, que fuese consentida, cuando no aprobada por el propio rey: «me llegan noti-

27 lbid., III, 1 ( $M G H$, Auct. Ant., XII,78): «quia populorum ferocium corda longa pace mollescunt, cavete subito in aleam mittere quos constat tantis temporibus exercitia non habere; terribilis est hominibus conflictus, si non sit assiduus et nisi uso praesumatur, concertandi subito fiduciam non habetur».

$28 \mathrm{Ibid}$., X,31 (MGH, Auct. Ant., XII, 319): «amare novimus viros fortes, qui saepius bella peregimus». Dice en el mismo discurso: «arma Gothorum nulla promissionum mearum varietate frangenda sunt... hoc sequi promittimus quod onet regium nomen... postremo omnia pollicentur imperium, quale Gothos habere debeat... quandiu enim fortes viri inter bella ferventia nutriti principem ferre poterant non probatum, ut de eius fama laboraret, quanvis de propria virtute praessumere?».

${ }^{29}$ Ibid., I,24 (MGH, Auct. Ant., XII,27): «innotescenda sunt magis Gothis quam suadenda certamina, quia bellicosae stirpi est gaudium comprobari: laborem quippe non refugit, qui virtutis gloriam concupiscit... latet enim sub otio laudabilis fortitudo et dum se probandi non habet spatium, occulta es lux tota meritorum». Adopta por hijo al rey de los Hérulos por su valor guerrero, porque «per arma fieri posse filium...qui non est dignus adoptari, nisi qui fortissimus meretur agnosci... et ideo more gentium et conditione virili filium te praesenti munere procreamus, ut competenter per arma nascaris, qui bellicosus esse dignosceris» (ibid., IV,2; MGH, Auct.Ant., XII, 114). Alaba al rey de los Warnos porque sus gentes «ferro magis quam auri pretio ditiores» (ibid, $\mathrm{V}, 1 ; M G H$, Auct. ant., $\mathrm{XII}, 143$ ). Con su política matrimonial espera conseguir «quod per bella solebat quaeri» (ibid., V,44; MGH, Auct. Ant., XII, 171). 
cias -dice- de que vos (el rey) decís que estas rapiñas y expolios no son asunto vuestro y que cada cual defienda lo suyo como pueda ${ }^{30}$. Más duro aún es el monje Abbo, que no duda en llamar a todos los hombres públicos, del rey para abajo, «sacrílegos, salteadores y ladrones violentos», exhortándoles a que vivan de la justicia y no de sus rapiñas ${ }^{31}$.

Sería, sin embargo, un error (o peor, una simpleza) explicar la amplitud y asiduidad de los saqueos llevados a cabo por los invasores y sus descendientes por un supuesto «espíritu de codicia», como hicieron frecuentemente sus contemporáneos, tan aficionados a atribuir vicios congénitos a determinados pueblos $^{32}$. Tales recursos psicológicos no suelen hacer nunca justicia a la realidad y, en todo caso, son siempre aleatorios, subjetivos y extremadamente difíciles de probar con un mínimo rigor, por más que haya historiadores que se sigan empeñando en usarlós a propósito de otras cuestiones. Hay que tener en cuenta, sin duda, factores de otra índole y especialmente algunos de orden estructural. Ante todo, que las primeras monarquías bárbaras surgidas de las invasiones no dispusieron nunca (y menos aún en sus inicios) de un ejército regular ni de fuentes estables de ingresos para financiarlo: cada grupo debía procurarse a sus expensas la manutención, el armamento y otros medios de guerra, cuando iba de campaña. Por otro lado, la burocracia al servicio de los nuevos señores, generalmente compuesta por funcionarios romanos que conservaban algunos restos de la organización imperial, fue rudimentaria y escasa; incluso fue cada vez más reducida, a medida que desaparecían sus fuentes de ingresos y sus campos de acción. Además, y como consecuencia precisamente de las devastaciones y desorganización inicial, con pérdida de vidas y bienes, llegó a desa-

30 HinCMAR DE REIMS, De coercendis militum rapinis (PL 125,955 C-D): «quia per plurimorum ora vulgatur vos (el rey) dicere, quoniam de istis rapinis atque depraedationibus nihil vos debeatis misculare, unusquisque sua defendat ut potest». No debe sorprender esta respuesta del rey, que recoge Hincmar, pues en la Alta Edad Media tener un derecho y ser capaz de mantenerlo eran la misma cosa; los derechos ciudadanos no estaban vinculados a las personas, sino a su capacidad de adquirirlos y mantenerlos, incluso por la tuerza (cfr. M. GARCLA PELAYO, Del mito y de la razón en el pensamiento político (Madrid 1968) p, $85 \mathrm{ss.}$

31 ABBO, Sermo V (PL 132,774 A-B): «quottidie dissipant illi qui nunc sunt principes mundi, reges videlicet, comites, vicecomites, consules, proconsules, eorumque vicarii... omnesque mali judices. Aufenant namque perversa calliditate urbalibus ecclesiis, necnon monasteriis, res et villas... praedis scilicet, rapinis, precariis falsidicis, manufirmantibus iniquiis... Interdum vero violenter easdem res diripiunt. Sunt tales sacrilegi, praedones, violenti raptores». Cfr. Sermo IV (PL 132,770 B): «ergo necesse est vobis ut studeatis vivere de vestra justitia, no de rapina».

32 Salviano de Marsella, más moralista que historiador, es quizá el mejor exponente de esa historia "psícologizante» de los primeros tiempos bárbaros: «praetermitto -dice- in aliquo rabiem cupiditatis, vitium totius generis humani; praetermitto avaritiae inhumanitatem, quod propium est romanorum pene omnium malum... Gothorum gens perfida, sed pudica est; Alanorum impudica, sed minus perfida; Franci mendaces, sed hospitales; Saxones crudelitate efferi, sed castitate mirandi; etc.) (De gubernatione Dei, VII,15; PL 53, 142 B-C). Otros muchos siguieron ese tipo de interpretación.

Proyección internacional de la iglesia hispana Hispania Sacra 51 (1999) 
parecer la fiscalidad directa que había mantenido el Bajo Imperio; más aún, si cabe, la indirecta (excepto en algunas pocas zonas), con el práctico colapso del comercio, provocado por el agotamiento de recursos, la inseguridad y el deterioro de las comunicaciones. Finalmente, la moneda dejó de circular y sólo algunos reinos acuñaron moneda de tipo imperial, pero en poca cantidad y por breve tiempo ${ }^{33}$.

Todo ello produjo fenómenos de tesaurización, comunes a los diversos reinos bárbaros, que reforzaron la idea de que acumular riquezas era consolidar el poder, descuidando más si cabe el fomentar la reconstrucción, la producción agraria y artesanal, el comercio y otras fuentes de ingresos, que hubieran permitido restaurar una fiscalidad más estable y organizada. La riqueza y los medios de la monarquía, así como la de los grupos que la componían, se obtenía de modo inmediato allí donde se encontraba: sólo bastaba disponer de la fuerza suficiente para cogerla, con expoliaciones y saqueos ${ }^{34}$. Los recursos así allegados no revertían a una población esquilmada, por carecerse del concepto de obra pública ${ }^{35}$; eran absorbidos en su integridad por el rey y por su corte, que tenían que obtenerlos constantemente con nuevos expolios, si los había y mientras los hubiera.

\section{II.- EL PROYECTO DE TEODORICO-CASIODORO}

En estas circunstancias, no es extraño que hombres bien preparados, que habían conocido otras formas de organización política y de ejercicio del poder, quisieran servirse de su influjo para moralizar la vida pública de los nuevos reinos a que pertenecían. Pero el contraste entre el mundo bárbaro emergente y

33 Uno de ellos fue precisamente el reino suevo del noroeste de España, donde vivió y escribió Martín de Braga; cfr. C.A. GUADAN, Las copias suevas de los sólidos de Honorio (Porto 1958).

34 Los movimientos de refugiados y deportados, la miseria, la reconstrucción y otros fenómenos similares son, con frecuencia, más importantes para conocer una época que muchos problemas de derecho o de linglística; pero, por desgracia, las fuentes que nos han llegado nos hablan poco de esas cuestiones. Para la Península Ibérica han recogido algunos datos C. SANCHEZ ALBORNOZ, Ruina y extinción del municipio romano (Buenos Aires 1943) y P. DAVID, Etudes historiques sur la Galice et le Portugal du VI et VIF siecle (Lisboa 1947). En general, pude decirse que los primeros reinos bárbaros se desinteresaron de la reconstrucción (poblaciones, comunicaciones, etc.), base de toda la creación posterior de riqueza. Los reyes se limitaron a conceder algunas desgravaciones fiscales en los casos más graves y en algún núcleo urbano donde establecieron su corte; pero en la mayoría de los casos, no fue la monarquía, sino otras instancias, las que hicieron alguna labor reconstructora: Benevento, destruida por Alarico, fue restaurada modestamente por un particular ( $C I L$ IX,1956); algo parecido hizo el obispo Eusebio en Milán; Teodorico parece ser una excepción, preocupado por embellecer Roma.

35 Según Casiodoro, sí existió en el reino ostrogodo. 
el mundo romano en desintegración distaba mucho de limitarse a los aspectos más visibles y calamitosos del período de invasiones y de primeros asentamientos. Con éstos entró también en la vida política un patrimonio nuevo de ideas sobre la sociedad y su vertebración, sobre el poder y su ejercicio, que era relativamente simple comparado con el romano, pero que se le opuso eficazmente y acabó convirtiéndose en el núcleo alrededor del cual se elaboraron las formas políticas de la Alta Edad Media. Ya desde los primeros tiempos no se trataba sólo de frenar la violencia y la rapiña, sino también de algo más: de transformar el tradicional Kuning bárbaro, vínculo con la divinidad y caudillo victorioso de tropas, en un rex o verdadero gobernante; de transformar la $\mathrm{Si}$ ppe, estirpe soberana de los pueblos germanos, en un verdadero populus-gens o sociedad vertebrada y unida por la idea de ciudadanía más que por la raza ${ }^{36}$. Sólo así parecía posible que los nuevos reinos que comenzaban a surgir se dotasen de una estabilidad territorial, de unas instituciones y de un poder que hiciesen posible la convivencia. La latinización de éstos y de otros términos fundamentales para la vida política no había sido un mero fenómeno de traducción y acabaría siendo una verdadera mutación semántica, que apuntaba a la propia organización de los nuevos reinos.

1.- Son los godos de Ataúlfo (+415) los primeros de quienes consta que intentaron dicha transformación. Sucesor del temido y denostado Alarico, que tan negativa impresión había dejado en los hombres del Bajo Imperio, Ataúlfo intentó fusionar a los godos y a los romanos en una nueva organización política, haciendo de su pueblo el centro y motor del nuevo imperio que proyectaba. Lo que había sido Roma para Occidente lo intentaría ser, en adelante, el nuevo reino godo establecido en las Galias. Pero esto hubiese exigido introducir no-

36 Para el conocimiento de las estructuras sociales y políticas del mundo germánico siguen siendo básicas las obras de $\mathrm{O}$. HöFLER, Germanisches Sakralkönigtum (Friburgo-Colonia 1952) y R. WENSKUS, Stammesbildung und Verfassung. Das Werden der frühmittelalterlichen Gentes (ColoniaGraz 1961). Baste recordar aquí que la organización política germana reposaba sobre una idea central: que la coherencia de la sociedad y del poder estaban garantizados por fuerzas objetivas, independientes de la voluntad humana. Esto implicaba la convicción mítica (expresada en los carmina y en los nomina de que ya hablaba Tácito, Germ. II,39) de que todos los miembros de una estirpe (Sippe) descendían del mismo progenitor divino y participaban así de una misma substancia, que los identificaba entre sí y los distinguía de los otros hombres (concepción mítica que se dio también en otras civilizaciones antiguas). En ese grupo de consanguíneos de origen divino residía la soberanía, que se afirmaba y ejercía a través de la Asamblea de sus miembros. La función regia tenía un carácter marcadamente sacro: más que en gobernar consistía en asegurar el vínculo entre la estirpe y los dioses; y ese vínculo se consideraba garantizado si el rey (Kuning) proporcionaba victorias y bienes abundantes (cfr. AM. MARCEL, Hist., 28,5; TAC., Germ., 7). Esta idea central se mantiene durante el largo período de invasiones y primeros reinos barbaros (cfr. P. DELGU, «Germanos y Carolingios», en L. Firpo dir., Storie delle idee politiche, economiche e sociali, Turin 1983, I-2, 3 ss.). La violencia y la rapiña, como he dicho, no eran meros episodios coyunturales, sino que tenían una razón de ser también estructural.

Proyección intemacional de la iglesia hispana

Hispania Sacra 51 (1999) 
tables transformaciones para las que no estaban todavía preparados, al parecer, los hombres de Ataúlfo. Según las escasas noticias que tenemos, éste comprendió que la confrontación permanente entre romanos y godos, o entre éstos con otros pueblos bátbaros, carecía de futuro y se perdía en una sangría estéril de vidas y bienes. Comprendió también que el carácter universal de la civilización romana, base de su imperio, era radicalmente distinto del particularismo de la estirpe (Sippe) de los pueblos germanos y que sólo dotando a los godos de ese carácter universal, bajo la primacía de su dominio, podía sustituir la Romania por la Gothia y crear un nuevo imperio ${ }^{37}$. Para ello unió a los godos dotándolos de leyes tomadas de Roma, intentó someter a otros pueblos, pactó con el emperador Honorio y se casó con su hermana Gala Placidia. Este era sólo el comienzo, pero nada de ello surtió el efecto duradero que esperaba y pronto comprendió que no bastaba con establecer una equivalencia entre el mundo godo y el romano, porque éste no había basado su cohesión en la estirpe, como los bárbaros, sino en el dominio objetivo de las leyes; no era fruto de la sangre, sino de la voluntad ciudadana. Convencido finalmente de que «los godos no podían obedecer leyes, por causa de su desenfrenada barbarie, y que tampoco convenía derogarlas, pues sin ellas el Estado no es tal, eligí para sí al menos la gloria de restaurar íntegramente el imperio romano y engrandecerlo con la ayuda de los godos, y ser tenido por la posteridad como artífice de la restauración romana, ya que no había podido ser su innovador» ${ }^{38}$.

37 O. BERTOLINI, «Gothia e Romania» en 1 Goti in Occidente (Spoleto 1956) 357 ss. Sobre Ataúlfo sigue siendo básica la obra de L. SCHIMIDT, Die Ostgermanen (Berlín $1941^{2}$ ) pp. 67 ss. Consecuencia de la idea de comunidad de sangre con origen divino era que la esencia del grupo o estipe (Sippe) se designara mediante un distintivo moral o mútico: los godos eran los «hombres consagrados a Gautan-Wotan», dios que ayuda en la guenra; Fredegardo recoge una tradición que así lo expresa, cuando dice la fórmula «qui instituerat nomen concidere victoriam» (quien -Wotan- les dio el nombre les conceda la victoria; MGH, Auct. Renum Merov. II,110, FRED. II,65). Pero dicha concepción tenía otras consecuencias: los comportamientos fijados por normas, como reglas o usos generales que dictan lo que debe ser o suceder, valían sólo en el interior del grupo (cfr. F. GENZMER, «Die gernnanische Sippe als Rechtsgeschichte», ZRG, 67, 1950, pp. 34 ss. y K. HAUCK, aLebensnormen und Kultmythen in germanischen Stammes- und Herrschergenealogien», Saeculum, 6, 1955, pp. 186-223); en lo exterior, el derecho no tenía razón de ser y era lícito el engaño, la violencia, la rapiña, etc. El imperio, por el contrario, era una comunidad política ecuménica o universal, no basada en la afinidad de sangre o en las costumbres, sino en el concepto jurídico de citudadania y en el moral de civilización («ordo romanus»); el poder se revestía de una magistratura o función pública, sometida a unas pautas, y el conjunto era dominado por el imperio de la ley; fuera de ello, todo se consideraba barbarie y paganismo. De todos modos, el concepto germano de norma era mucho más amplio que el romano de norma jurídica.

38 OROS., Hist., VL,43 (PL 31, 1667): «...ut obliterato Romano nomine, Romanun omne solum, Gothorum imperium et faceret et vocaret: essetque, ut vulgariter loquar, Gothia, quod Romania fuisset, fieretque nunc Ataulphus, quod quondam Caesar Augustus. At ubi multa experientia probavisset, neque Gothos ullo modo parere legibus posse propter effrenatam barbariem, neque reipublicae interdici leges oportere, sine quibus respublica non est respublica; eligere se saltem ut gloriam sibi de 
2.- El proyecto de Ataúlfo dưó los escasos cinco años de su reinado y desapareció sin dejar más huella visible que las secuelas de algunas guerras. Sus sucesores inmediatos, que sepamos, no volvieron a intentar nada parecido. Sólo un siglo después, los godos de Teodorico el Grande (+526) estuvieron en condiciones de asentarse en Italia, con el acuerdo del emperador, y de dominar Ia propia Roma. Durante dos decenios el rey y algunos romanos que colaboraron con él diseñaron un nuevo proyecto, arropado por una intensa labor ideológica, para hacer coincidir de modo institucional y organizado la nueva conciencia de unidad y predominio germano con el prestigio y estabilidad del mundo romano. Protagonistas de este nuevo intento fueron Boecio $(+524) \mathrm{y}$, sobre todo, Casiodoro. Este último es el verdadero motor y artífice de la configuración del reino ostrogodo, que hubiera podido servir de modelo a los demás reinos bárbaros que se asentaban lentamente por entonces. Era un intelectual de amplia formación clásica, pero dedicado la mayor parte de su vida a la política. Desde los altos cargos públicos que ocupó, pero especialmente desde la cancillería regia, realizó una importante labor de gobierno y doctrinaria, que ha quedado plasmada en numerosas cartas, edictos, nombramientos, reconvenciones, concesión de dignidades y fórmulas curiales, escritas en nombre de Teodorico y dirigidas a otros reyes bárbaros, al emperador o a numerosas instituciones y cargos públicos ${ }^{39}$.

No sabemos si Casiodoro oyó hablar del proyecto de Ataúlfo, pero en todo caso rechazó la idea de sustituir al Imperio o de volverlo a instaurar en Occidente, desgajándolo nuevamente de Oriente. Pasado más de un siglo desde las invasiones, la situación de Italia y del resto de la Europa occidental había cambiado y todo parecía indicar que los pueblos asentados en ella se habían

restituendo in integrumn, augendoque Romano nomine Gothorum viribus quareret, habereturque apud posteros Romanae restitutionis auctor, postquam esse non potuerat inmutator. Ob hoc abstinere a bello, ob hoc inhiare paci nitetabur, praecipue Placidiae uxoris suae... ad omnia bonarum ordinationum opera persuasu et consilio temperatus». Orosio es la única fuente que habla de este proyecto de Ataúlfo. Lo había oido contar a un prominente narbonés, cuando estaba en Jerusalén con S. Jerónimo.

39 Esa abundante documentación puede verse en las ya mencionadas PL y MGH $=M$. Aurelii Cassiodori Variarum libri doudecim, PL 69, 501 ss. y Th. MOMMSEN, Cassiodori Senatoris Variae, MGH, Auct. Antiquiss. XII-1, 1 ss. (Yo sigo aquí la edición de Mommsen). Casiodoro fue Prefecto de Lucania, Cuestor, Magister, Prefecto el Pretorio, Senador, etc.; como Canciller regio escribio no sólo en nombre de Teodorico, sino de sus sucesores: Alarico (+535) y su madre Amalasunta (+534), Teodato (+536) y Vitiges (+542). Tras la caida de éste, puso fin a su vida pública y se retiró al monasterio de Vivarium, que él mismo había fundado. El proyecto de reino ostrogodo se gestó en tiempos de Teodorico, pero las ideas en que se sustentaba siguieron repitiéndose en los reinados posteriores, cada vez con menos éxito, como es sabido, y con mayor desfase entre el ideal propuesto y la realidad del reino. Este ha sido bien estudiado por W. WOLFRAN, «Gothisches Königtum und römisches Keisertum von Theodoricus dem Grossen bis Iustinian I», Frühmittelalterliche Studien, 13 (1979) 78 ss.; puede verse también la obra ya citada de L. Schmidt, pp. 83 ss.

Proyección internacional de la iglesia hispana

Hispanja Sacra 51 (1999) 
afianzado tanto que era ya imposible una vuelta al pasado. Casiodoro, pues, piensa que hay que establecer las instituciones civiles, adaptar las leyes y costumbres romanas y unificar la fragmentada Italia ${ }^{40}$. Pero todo ello exigía, a su vez, no sólo abandonar definitivamente un estilo de vida itinerante, inestable y en buena medida aventurero, como ya empezaba a suceder, sino establecer una convivencia pacífica y organizada, ejerciendo el poder sin la improvisación y la arbitrariedad que marcaban los impulsos mutables de las estirpes y sus caudillos o el hilo quebradizo de los acontecimientos. Era necesaria, pues, una planificación para los godos, "porque no es de hombres sabios despreciar las cosas que han de ser útiles» ${ }^{41}$; y esto exigía del rey rodearse de consejeros prudentes que, con su sabiduría, contribuyeran al bien de todos ${ }^{42}$. Pero especialmente era necesario cambiar muchas cosas en los usos y costumbres de los pueblos invasores: dotarlos de nuevas pautas de conducta y de nuevas nornas de convivencia estables, tomadas de la mejor tradición romana y de los «logros de la antigüedad», incluso recurriendo a la fuerza, ya que «siempre debe estar preparado el que quiera contener a los bárbaros, porque sólo el temor frena a aquéllos a quienes no detiene la palabra dada» ${ }^{43}$. Se trataba, pues, de implantar la fides pública romana como base de una nueva convivencia y seguir unas reglas establecidas (regulas constutas) que habían atestiguado su validez.

Para inculcar las ideas que hicieran posible esta ambiciosa transformación, Casiodoro se va a servir de su propio ascendiente y de los cargos ocupados en la corte ostrogoda. Pero no escribe un tratado político sobre el Estado ideal, sus instituciones y sus leyes, como ya habían hecho Platón, Aristóteles o Cicerón; tampoco va a escribir un manual de virtudes públicas para gobernantes, como harían posteriormente los llamados «espejos de príncipes». Su intento educador y moralizador es eminentemente práctico y va unido al desempeño

40 CAS., Var. I,1 (MGH, Auct. Ant., XII,10): «regnum nostrum imitatio vestra est, forma boni propositi, unici exemplar imperii; qui quantum vos sequimur, tantum gentes alias anteinus; hortamini me frequenter, ut diligam senatum, leges principum gratanter amplectar, ut cuncta Italiae membra componam... Romani regni unum velle, una semper opinio sit» (carta del affo 508 al emperador Anastasio). Este escrito es una breve declaración programática.

41 Ibid. II,7 (MGH XII,50): «quia non est sapientiae profutura contemnere» (carta al conde Suna, escrita entre 508-511).

42 Ibid., II,6 (MGH XII,50): «deliberationis nostrae consilium virorum prudentium requirit obsequium, ut utilitatis publicae ratio sapientium ministerio compleaturs (carta al patricio Agapito, affo 509-511). El proyecto exigía sustituir la Asamblea de la estirpe germana de sangre (cfr. n. 36) por un senado de hombres escogidos.

43 Ibid., II,4 (MGH XII,49): «delectanur vetustatis invento et sequi regulas constitutas libenter amplectimur, quia locus subreptionis non relinquitur, quotiens rationabiliter constituta servantur» (carta al noble Ecdicio, años 508-511); ibid. II,5 (MGH XII,50): «in procinctu semper erit, qui barbaros prohibere contendit: quia solus metus cohibet quos fides promissa non retinet» (carta al prefecto Fausto, años 508-511). 
cotidiano del ejercicio del poder en sus diversas ramificaciones y facetas: con ocasión de una guerra, de un conflicto o litigio, de un nombramiento, de una recompensa, de un castigo, pero introduciendo siempre principios y normas de buen gobierno en los documentos más variados que escribe en nombre del propio rey. Todo ello hace que sus ideas se vayan desgranando fragmentariamente o se repitan en circunstancias muy diversas; pero más allá de la dispersión, puede rastrearse quizá la lógica que las anima. Un somero análisis de su lenguaje es ya revelador; no es ahora el momento de hacerlo, pero son abundantes las expresiones como «buscar cuidadosamente la generosidad» (exquirere munificentiam), " amor de la clemencia» (amor clementiae), «utilidad del Estado» (utilitas reipublicae), «paz general» (generalis quietes), «derechos de la equidad» (aequitatis iura), «brillo de la virtud» (virtutis claritas), «garantía y compromiso público» (fides publica), «dichosísima tarea de estudiar» (felicissimus studiorum labor), «convenir a la justicia» (convenire iustitiae) y otras similares, que nos introducen en un orden de ideas y valores bien distintos de los descritos y criticados por los autores de esos siglos como propios de los pueblos bárbaros.

3.- A una sociedad belicosa y guerrera (cfr. pp. $8 \mathrm{ss}$.) se le propone como bien primordial la paz: «es necesario -escribe al emperador Anastasio- que busquemos la paz quienes sabemos que no tenemos motivos de cólera..., porque es verdaderamente deseable para todo el reino la quietud, en la que prosperan los pueblos y se salvaguarda el bien de las gentes ${ }^{44}$. Sentado este principio general, repetido de diversos modos en otros documentos, Casiodoro propone varios medios con los que el rey y sus hombres públicos ejercerán correctamente el poder para lograr la paz. Ante todo, haciendo valer el parentesco de los diversos grupos godos y aun de los pueblos bárbaros. Esto era especialmente comprensible para los germanos: el carácter sagrado de los vínculos de estirpe ${ }^{45}$ debía jugar a favor del entendimiento pacífico de los reinos bárbaros y no podía ser profanado con ninguna perturbación violenta ${ }^{46}$. Si esto no bastaba, quedaba para preservar la paz el recurso a una adecuada política matrimonial, que estrechase aún más los vínculos entre los diferentes pueblos y estirpes y la mútua aceptación de unos por otros ${ }^{47}$, al tener reyes y reinas

44 Ibid., I,1 (MGH XII,10): «oportet, clementissime imperator, pacem quarere, qui causas iracundiae cognoscimus non habere...; ornni quippe regno desiderabilis debet esse tranquillitas, in qua et populi proficiunt, et utilitas gentium custoditurn (carta al emperador Anastasio, año 508).

45 Cfr. n. 36.

46 CAS., Var., II,4 (MGH XII,80); «Ideo inter reges affinitatis iura, divina coalescere voluerunt, ut per eorum placabilem animum proveniat quies optata populorum; hoc enim sacrum est, quod nulla permittitur commotione violari» (carta al rey franco Clodoveo, año 507).

47. Ibid.,: «sociantur proximitate domini, ut nationes divissae simili debeant voluntate gloriari, et quasi per alveos quosdam concordiae adunata se possint gentium vota coniungere». El propio Teodo-

Proyección interracional de la iglesia hispana

Hispania Sacra 51 (1999) 
comunes. Si todavía esto era insuficiente para gozar de una paz duradera y un pueblo se alzaba contra otro, el buen gobernante debía intentar resolver el conflicto por medios amistosos, en evitación de males mayores a sus propias gentes y a las del enemigo; no debía llamar a las armas tras las primeras negociaciones fracasadas ni dar lugar a que su bravura y valentía (virtus), su cólera (furor) o su impaciencia (impatiens sensus) se convirtieran en una calamidad para su reino ${ }^{48}$. Sólo debía empuñar la espada una vez agotados todos los otros medios de conservar la paz y cuando ya es patente que «la justicia no puede tener cabida en el enemigo ${ }^{49}$. Incluso si ha sido inevitable la guerra, ésta no debe ser feroz, inhumana y de exterminio; una vez obtenida la victoria, el buen gobernante no debe ensañarse con los vencidos, sino poner pronto límite a la represalia y la venganza, moderando sus excesos: «moderad -dice a Clodoveo tras la victoria de Vouillé- vuestros ataques contra los restos (de visigodos) agotados por la guerra; sed indulgente con ellos; baste con haber sometido a un pueblo numerosísimo, muertos unos y hecho esclavos otros; a mí me han resultado un gran éxito las guerras que acabaron con final moderado; y es que vence siempre el que sabe moderar todas las cosas»s0.

Esta gradación, que puede parecer teórica y sin duda lo es, aunque Casiodoro no la desarrolle en una teoría, era para él resultado de la experiencia: así había visto que sucedía en algunos casos y quería propugnar que así fuese siempre; pero los hechos se encargarían, con frecuencia, de desmentirlo y los propios reyes a quienes se proponía esa doctrina no se dejaron convencer por ella. Es cierto que Teodorico logró establecer algunos vínculos entre los godos

rico dio ejemplo, casándose con una hija de Clodoveo para estrechar los lazos entre godos y francos; su hermana Amalafrida se casó con el rey vándalo Thrasamundo; su otra hermana Amalaberga con el de los Turingios; Clodeveo tambiér se había casado con una sobrina del rey de los burgundios; El visigodo Alarico II era su sobrino; etc. El hecho es que Teodorico ejerció un especial influjo sobre vándalos, burgundios, turíngios, hérulos, visigodos, etc. y que está en el centro de una política de enlaces en la que algunos han querido ver un intento de hegemonía "patriarcal», que prolonga en algunos aspectos la romana y tiende puentes hacia la medieval. Pese a ello, las buenas intenciones de Teodorico-Casiodoro quedaron frecuentemente estériles: sólo Clodoveo mandó asesinar, que se sepa, a Sigiberto, Cloderico, Cararico, Ranacario, Ricario y Rignomiro, todos ellos reyes de diversos pueblos francos y parientes del propio Clodoveo.

48 lbid:: «virtus vestra patriae non fiat inopinata calamitas...; dicam libere, dicam affectuose quod sentio: impatiens sensus est ad primam legationem protinus anma conmovere»; cfr. ibid., III,24 (MGH XII, 92): «quid opus est homini lingua, si causam manus agat armata?; ait unde pax esse creditur, si sub civilitate pugnetur?» (carta a todos los bárbaros y romanos de Pannonia, año 507-511).

49 Ibid., III,1 (MGH XII,78): «tunc utile solum est ad arma concurrere, cum locum apud adversarium justitia non potest invenire» (carta al rey visigodo Alarico II, año 507).

50 lbid., II,41 (MGH XII,73): «motus vestros in fessas reliquas temperate...; estote illis remissi...; sufficiat innumerabilem nationem partim ferro, partim servitio subjugatam...; illa mihi feliciter bella provenerunt, quae moderato fine peracta sunt; is enim vincit assidue, qui novit omnia temperare» (carta al rey franco Clodoveo, af́o 507). La batalla de Vouillé tuvo lugar ese mismo año. 
y otros pueblos; es cierto también que alcanzó pactos ventajosos que evitaron algunos enfrentamientos; durante unos años hubo una cierta «pax romana», hasta que el año 533 los francos se anexionaron por la fuerza el reino burgundio y dos años después la Provenza; para entonces, el propio emperador Justiniano había iniciado ya la reconquista de Occidente por las armas, se apoderaba del Africa bajo dominio vándalo y atacó a Italia durante veinte años, intentando poner fin al experimento de Teodorico. La pacificación pretendida por Casiodoro fue efímera y las guerras de unos pueblos bárbaros con otros o con el Imperio continuaron durante tiempo con la misma crudeza de siempre. Sus causas fueron confusas, pese a los esfuerzos de los historiadores por analizarlas. Casiodoro sólo alude a ellas de pasada y generalmente las atribuye a «vicios» o excesos de los gobemantes, a su actitud reprobable y, en substancia, a una cuestión de ética más que de política: es la cólera (furor), la ira (iracundia), la venganza (vindicta), la envidia (invidia), la codicia (aviditas) y otras pasiones similares de quienes mandan las que arrastran trágicamente a sus pueblos a una confrontación violenta. Con ello no hace sino recoger toda una tradición clásica de la que estaba imbuido. Una causa, sin embargo, destaca en ese panorama: la perfidia, que también otros escritores de la época reprochan a los bárbaros y especialmente a los godos; la facilidad para el engaño y la traición, para faltar a la palabra dada o incluso para esperar con disimulo la ocasión propicia de desencadenar un conflicto ${ }^{51}$, que entonces parecía reprobable, pero que acabaría siendo considerada como una virtud política.

4.- Si la paz exterior consiste en evitar la guerra, la paz interior de los reinos exige algo más: todo un complejo de elementos, que se engloban bajo la idea general de un cambio de costumbres para una nueva convivencia. Aquélla podía ser algo excepcional y, por tanto, también más fácilmente evitable; ésta afectaba a la vida cotidiana y debía ser cuidada con mayor esmero. De aquélla, aun la no deseada, podía surgir la gloria y el incremento del reino; de ésta sólo su ruina. Aquélla podía unir a un pueblo y hacerlo más fuerte ante los enemigos; ésta sólo dividirlo, empobrecerlo y aun aniquilarlo. El mayor elogio que Casiodoro cree poder hacer de un Prefecto es decir de él que consiguió «pacificar las costumbres bárbaras» ${ }^{52}$ y ésta es también la tarea más propia del gobernante: «mantener la concordia de todo su reino, porque se tiene por timbre

51 Ibid., III, 3 (MGH XII,79): «pessima consuetudo est despicere veritatem...» (carta circular a los reyes de los hérulos, los warnos y los turingios, año 507); ibid., III,2 (MGH XII, 79): "grave malum est inter claras regiasque personas, voluntates sibimet videre contrarias, et dissimulando spectare, ut de uno aliquid dolendum possit emergere» (carta al rey burgundio Gundebado, año 507); ibid,, II,41 (MGH XII, 73): «semper in auctoribus perfidiae resecabilis videtur excessus» (carta al rey franco Clodeveo, año 507).

52 lbid., II,15 (MGH XII,54): «superavit cuncta infatigabilis et expedita prudentia: traxit mores barbaros ad quietem» (carta al conde Venancio, año 507-511). El Prefecto alabado era padre del conde.

Proyección internacional de la iglesia hispana Hispania Sacra 51 (1999) 
de gloria del gobernante que la paz sea amada por todos; ¿qué cosa mejor escribe en nombre de Teodorico- se puede decir de mí que tener un pueblo en paz, un senado en armonía y todo el reino adornado con la dignidad de nuestras costumbres?» ${ }^{53}$. Esta es la meta a alcanzar. Pero así como en el exterior se puede preservar la paz por los medios señalados, en el interior del reino se podrá mantener sólo por la justicia y la equidad en el ejercicio del poder.

La justicia es algo fundamental para Casiodoro: debe ser salvaguardada en todas partes y fomentada por todos, pero especialmente por el gobernante, pues éste se fortalece con ella y desarma toda posible rebelión quitándole su causa ${ }^{54}$. Aquí, más si cabe que en otros aspectos de su proyecto, recoge los restos de la tradición grecolatina, plasmada en el viejo adagio: justitia est fundamentum regnorum. En el mundo clásico, la diké (justitia) comenzó siendo un concepto racional que designaba la conveniencia y proporción de dos magnitudes; su aplicación a la política se debe a los sofistas y especialmente a Protágoras, que la puso como base de la vida pública. Platón distinguió en ella un aspecto personal, que consistía en la obediencia debida del ciudadano a las leyes del Estado, y otro social, en la medida en que éste se constituía sólo por aquélla; ambos aspectos tenían, sin embargo, un denominador común: la idea de orden y racionalidad en la organización de la convivencia. Todavía Aristóteles distinguió entre derecho, o normativa pública para regularla, y justicia como virtud interpersonal ${ }^{55}$. Este es el marco de ideas en el que se desenvuelve Casiodoro; pero para él no se trata tanto de una virtud moral del individuo, sino de la virtud social por excelencia, que se identificaba desde Cicerón y Ulpiano con la justicia distributiva y se definía como «dar a cada uno lo que le corresponde» ${ }^{56}$. A un romano no hacía falta explicárselo, pero a un godo quizá sí y para ello casiodoro tenía dos opciones: seguir la tradición de los mejores tratadistas clásicos, lo que no entraba en sus cálculos, probablemente por te-

53 Ibid., I,23 (MGH XU,27): «decet regalis apicis curam, generalitatis custodire concordiam: quoniam ad laudem regnantis trahitur, si ab onnibus pax ametur; quid est enim quod nos melius praedicet, quam quietus populus, concor's senatus, totaque respublica monum nostrorum honestate vestita?» (carta a los patrícios Caeliano y Agapito, año 507-511).

54 Ibid., III,7 (MGH XII,83): «ubique decet justitiam custodiri...; omnes quidem justitiam colere et observare praecipimus» (carta al obispo Januario, año 507-511); ibid., III,1 (MGH XII,78): «justitia, quae reges efficit fortiores, cito convertit animos, qui contra se talis sentit armatos" (carta al rey visigodo Alarico II, año 507).

55 Los principales textos pueden verse en PLAT., Prot, 322a-324d; Krit, 49e-54d; Rep. 2,369a428a y 4,443c-e; Leg. 6,756c-757d; Gorg. 503d-504d; ARIST., Eth. Nic. 5,1130b-1131a y 1133b1134a. Han estudiado el concepto y su evolución F. SENN, De la justice et du droit (Paris 1927) y A. VERDROSS-DROSEBERG, Abendländische Rechtsphilosophie (Berlín 1962).

s6 «Suum cuique tribuere» (CIC., Inv. 2,35,160; Rep. 3,11,18; leg. 1,6.19; Off. 1,5,15; ULP., Dig. $1,1,10)$. 
mor a no ser comprendido ${ }^{57}$, o mostrar en qué consistía, mediante su aplicación a casos concretos que pudieran ser ejemplarizantes.

Gobernar con justicia consistiría, de modo general, en garantizar la seguridad y el bienestar de todos los ciudadanos, tanto romanos como godos, tanto cercanos a la Corte como provinciales; en impedir que sus vidas y sus bienes se vieran amenazados por otros súbditos, cualquiera que fuera su condición y poder; en conseguir que nadie en el reino ostrogodo viviera en la inseguridad, el temor o la indefensión frente a sus conciudadanos. Las amenazas externas se remitían a la cuestión de la guerra; ahora se trataba de las internas. Garantizar la seguridad y los bienes era sólo una propuesta de mínimos para una convivencia ordenada y pacífica; pero las tradiciones diferentes, los intereses contrapuestos y la desproporción de medios de los distintos grupos sociales para imponerlos exigían que esa justicia no quedara al arbitrio, a la «buena voluntad» o a la sola responsabilidad de los particulares o los grupos, tantas veces fracasada. Entre los germanos eran precisamente esos grupos quienes defendían sus vidas, sus bienes y sus derechos; en el nuevo Estado proyectado a imitación del Imperio debía ser una legislación clara y de eficacia comprobada como la romana, la que regulase las relaciones de los súbditos, «porque la autoridad de las antiguas leyes dicta las cosas que hay que respetar» ${ }^{58}$. Ellas establecían los derechos y los deberes públicos comunes a todos (iura publi$c a$ ). La intención de Casiodoro era inicialmente dotar de una legislación al pueblo godo y ésto se traducía para él en adoptar las leyes de Roma o parte de ellas; pero, en realidad, se trataba de imponerlas y esto suponía un cambio excesivamente abrupto para ser aceptado pacíficamente o incluso para ser comprendido. Así, hubo que negociar la convivencia: se recogieron leyes y usos germanos junto a leyes y usos del Imperio. No era éste un hecho completamente nuevo, pues, instalados en territorios donde la vida política, social y económica estaba reglada por leyes escritas, algunos reyes germanos com-

57 Por sorprendente que pueda parecer, el propio Teodorico no tenía posiblemente suficiente cultura, pese a haber sido un auténtico mecenas. El Anónimo Valesiano, que a veces es panegírico más que historia, no tiene reparo en ser irónicamente cruel, cuando nos dice que el rey ostrogodo seguía siendo incapaz, después de diez años de reinado, de aprenderse las cuatro letras (legi) de autentificación de los decretos que le preparaba Casiodoro: «igitur rex Theodoricus inlitteratus erat et sic obruto sensu, ut in decem annis regni sui quattuor litteras suscriptionis edicti sui discere nullatenus potuerat” (Anon. Val., 24; E. BARTOLINs, I barbari, Milán 1982, p. 300).

58 CAS., Var. I,27 (MGH XII,29): «exterarum gentium (los bárbaros) mores sub lege moderamur...; juri Romano servit quidquid sociatur Italiae" (carta a Specioso, año 509); ibid., II,18 (MGH XII,56): «priscarum legum reverenda dictat auctoritas» (carta a los poseedores etc. de Trento, año 507-511); ibid, IV,12 (MGH XII,119): "propositi nostri est ut provincias nobis, Deo auxiliante, subiectas, sicut armis defendimus, ita legibus ordinemus: quia semper auget principes observata justitia et quantum probabili institutione vivitur, tantum sumrnis adhunc provectibus aggregatur» (carta al conde Marabado y al senador Gemello, año 508-511).

Proyeccion internacional de la iglesia hispana

Hispania Sacra 51 (1999) 
prendieron la conveniencia de hacer redactar también los usos y costumbres de sus pueblos, transmitidos hasta entonces oralmente ${ }^{59}$. Teodorico fue más lejos e, imitando la labor legislativa de los últimos emperadores, mandó redactar «breviarios» para uso de sus súbditos ${ }^{60}$, seleccionando o adaptando lo que creyó más útil para mantener la paz en el interior del reino «porque no hay resquicios para una conducta torcida donde se cumplen las leyes establecidas por la razón» ${ }^{61}$.

5.- No bastaba, sin embargo, con disponer de una buena legislación, aunque ésta se hubiera revelado eficaz en el pasado para ordenar la convivencia; había además que aplicarla correctamente. Y esto por varias razones: en primer lugar porque la ley escrita no siempre es clara y unívoca, puede interpretarse de diversos modos y suele dar lugar a nuevos conflictos; además porque la ley escrita no puede abarcar todos los aspectos de la convivencia ni regular todas las posibles conductas; sobre todo, porque la «opinión» legal no coincide siempre con la social, puesto que hay conductas que la sociedad considera reprobables y para la ley son irrelevantes o viceversa. La ley selecciona sólo unas conductas que ve como beneficiosas o perjudiciales y las precisa en normas; propone

59 Sólo Jordanes (Getica, 11), que sepamos, menciona una excepción a esa tradición oral: las enigmáticas leyes balaginas, que no han podido ser identificadas con certeza. Ese proceso hacia una plasmación escrita de los usos y costumbres germanos ha sido bien estudiado por B. PARADISI, Storia del Diritto (Nápoles 1951) pp. 245 ss. Sabemos tambiên que el visigodo Eurico (+484) había hecho componer un código para su pueblo (cfr. R. BUCHNER, Die Rechtsquellen. Vorzeit und Karolinger, Weimar 1953, pp. 7-8; A. D'ORS, «La territorialidad del derecho de los visigodos», en Settimane, Centro italiano di Studi sull'Alto Medioevo, Espoleto 1956, III,389 ss.; ID., El Código de Eurico, Roma-Madrid 1960); el burgundio Gondebado hizo componer un Liber Constitutionum o Lex Gondebada, recogiendo decretos de su predecesor Hilperico (+475; cfr. R. BUCHNER, o.c., pp. 5-6).

60 Es conocido su Edictum Theodorici (cfr. R. BUCHNER, o.c., pp. 13-14). Por los mismos años hicieron algo similar el visigodo Alarico II con su Lex Romana Visigothorum, conocido también por Breviario de Alarico o Breviario de Aniano (cfr. R. BUCHNER, o.c., pp. 9-10) y el ya mencionado Gondebado con su Lex Romana Burgundionum, (ibid., pp. 12-13). Para esta labor se llamó a juristas como León de Narbona, Aniano, Siagrio y otros que no han salido del anonimato. Esos breviarios recogían fragmentos de los Instituta de Gayo, de las sentencias atribuidas a Paulo, del código del emperador Teodosio, de las «novellae» posteriores, etc. Para una visión general de la influencia del derecho romano en los reinos bárbaros sigue siendo básica, pese a su antigüedad, la obra de $\mathbf{K}$. von HALBAN, Das römische Recht in den germanischen Volksstaaten (Breslau 1899). Existen también monografías sobre reinos particulares, que omito por no interesar aquí tanto las cuestiones técnicas como subrayar que Casiodoro vio en el derecho romano un medio de racionalizar $y$, por tanto, moralizar la vida pública; pero hay que añadir que el derecho destinado a los germanos está influenciado no tanto por el romano clásico cuanto por el «provincial», menos alejado de aquél; cfr. E. LEVY, «Vulgarisation of Roman Law in the early Middle Age», Medievalia e Humanistica, 1 (1943) 14-40; F. NIEACKER, Vulgarismus und Klasicismus im Recht der Spattantike (Gotinga 1955) passim.

61 CAS., Var., II,4 (MGH XII,49): «sequi regulas constitutas libenter amplectimur, quia locus subreptionis non relinquitur, quotiens rationabiliter constituta servantur» (carta al noble Ecdicio, año 508-511). 
unos bienes y persigue unos males, pero no todos; da normas generales, pero no puede prever cada caso. En consecuencia, la ley deja unos amplios márgenes al gobernante y sus ministros para ejercer correctamente o no su poder. En esos márgenes debía entrar nuevamente en juego la consideración del bien común (utilitas publica, generalis utilitas, communis utilitas) como en la propia ley escrita, «porque al príncipe le corresponde el cuidado de lo que concierne a la prosperidad del reino» y para ello debe elegir «lo que es digno de ser aprobado por todos»; y no sólo el príncipe, sino cuantos ejercen algún poder deben también, a imitación suya, «dedicarse con éxito a lo que ven que puede ser de utilidad pública» ${ }^{62}$. Con ser ya mucho, tampoco esto basta todavía y el buen gobernante deberá llenar el margen discrecional que le dejan la ley y el bíen común con dos virtudes propias de quien ejerce el poder: la equidad y la clemencia. Casiodoro pasa así del plano objetivo de la ley al subjetivo de la virtud.

Justicia (justicia) y equidad (aequitas) son usadas, a veces, como sinóni$\operatorname{mos}^{63}$, pero en realidad son distintas. En Roma el jus pretorium contenía ya elementos de la equidad, al dejar margen al pretor para decidir las cuestiones civiles atendiendo a la epiqueya; es decir, a la interpretación de una norma jurídica según las circunstancias de tiempo, lugar y persona. La equidad se superponía al principio inflexible dura lex sed lex, porque aplicaba el derecho al margen de su estricta literalidad, ya se tratase de normas existentes (positivas o consuetudinarias) o de unos esquemas ideales de justicia (racionales o «naturales»). Pero además de ser necesaria para aplicar correctamente la ley a casos concretos, la aequitas era también necesaria en el gobernante por otras razones: para que el ordenamiento establecido por la ley constituya, de hecho, una verdadera garantía jurídica para todos, porque «es segura la condición de los súbditos donde se vive bajo la equidad de los gobernantes»; para evitar la venganza y el ensañamiento en la persecución de los delitos, porque «ien qué se distingue el culpable de aquél que se empeña en castigar con exceso?»; para que la ley no se aplique con doble medida, lo que hace insegura la convivencia y desmoraliza a la sociedad, porque «la justicia digna de tal nombre es la que se aplica por igual a los poderosos y a los humildes» y «nadie se esfuerza por

62 Ibid., 1,6 (MGH XII,16): «decet principem cura quae ad rempublicam spectat augendam» (carta a Agapito, prefecto de Roma, año 507-509); ibid., I,12 (MGH XII,20): «Ut illud magis aestimemur elegisse, quod cunctos dignum est approbare" (carta a Eugenito, magister offcionum, año 507511); ibid., II,20 (MGH XII,57); «omnes decet gratanter impendere, quod publicas videt utilitates posse respicere, quando necesse est hoc membra sentire, quod corporis summa sentitur" (carta al sajón Uniligo, ā̄o 507-511).

63 Debido probablemente a una reminiscencia de la ambigutuedad del término «justitia-diké», señalada ya por Aristóteles (Eth. Nic. 5,1), que podía designar tanto lo que es conforme a la ley como lo que es igual o equilibrado.

Proyección internacional de la iglesia hispana Hispania Sacra 51 (1999) 
castigar los pequeños delitos, si ve que aun los más graves quedan impunes» ${ }^{64}$. Hay todavía otra razón, dirigida de modo especial a los germanos: para éstos el ejercicio de la justicia se daba sólo entre iguales y correspondía a la estirpe, a sus jefes o a sus familiares, el castigar las ofensas; para el derecho romano era una función pública que correspondía al Estado, común a todos, y a sus representantes; para Casiodoro es también así, por lo que corresponderá igualmente al gobernante y a sus ministros velar por la justicia de todos sus súbditos, aunque sean desiguales $o$ inferiores ${ }^{65}$.

Por todo ello es grave la responsabilidad de los jueces, que representan al rey en la administración de la justicia: éstos no pueden aplicar las leyes a su antojo, sino en el modo y medida definidos por ellas; deben impartir una «justicia ecuánime» en el sentido dicho y deben prescindir de otros intereses o conveniencias, porque «para (salvaguardar) los derechos de la equidad nadie mejor es elegido que aquél que, por amor a la justicia, es incapaz de juzgar por razones personales $\mathrm{y}$, amando a todos en conjunto, no da lugar a agravios comparativos» ${ }^{66}$. Pero tampoco basta con todo lo dicho: pueden existir leyes justas, pueden aplicarse con equidad y todavía para lograr una buena convivencia debe quedar margen para la piedad y la clemencia del gobernante, del rey. Su principal preocupación en esta materia debe ser prevenir más que curar, porque «es propio de un príncipe benigno no tanto querer castigar los delitos cuanto evitar que se produzcan ${ }^{67}$. Debe advertir cuando todavía es tiempo, si tiene conocimiento o sospecha de una acción reprobable, para no tener

64 CAS., Var. I,9 (MGH XII,18); tuta est conditio subiectorum, ubi vivitur sub aequitate regnantium» (carta a Eustargio, obispo de Milán, año 507-511); ibid. I,30 (MGH XII,31): «quid enim discrepat a peccante, qui se per excesum nititur vindicare?» (carta al Senado romano, año 507-511); ibid., I,10 (MGH, XII,18): «justitia quae sic nominis sui obtinet dignitatem, si aequabili moderatione per potiores currat et humiles» (carta a Boecio, año 507-511); ibid., II,14 (MGH XII,53): «nec aliquis nititur, quod parvum est vindicare, si delicta summa respiciantur evadere» (carta al patricio Symaco, ā̄o 507-511).

65 Ibid., I,8 (MGH XII,17): «cordi nobis est cunctos in commune protegere, sed eos maxime quos sibi novimus defuisse; sic enim aequitatis libra servabitur, si auxilium largiamur imparibus" (carta al procurador Amable, año 507-511).

66. Ibid., I,23 (MGH XII,27): «quibus (actionibus) pro legum ratione susceptis, et si juris ordo patiatur, definitis...; videte ergo tanti judicii arbitros vos electos: videte expectationem nostram aequabilem flagitare iustitiam»(carta a los patricios Celiano y Agapito, afio 507-511); ibid., I,8 (MGH XII,50): «quis melius ad aequitatis iura deligitur quam...qui amore iustitiae personaliter nescit iudicare, et diligens cunctos in commune, locum non reliquit invidiae?» (carta al obispo Severo, año 508).

67 Ibid., I,7 (MGH XII,17): «ne nos hiusmodi factum cogas legibus vindicare, qui nunc videmur omnia mansuetudine temperasse» (carta al conde Félix, año 507-511); ibid., I,30 (MGH XII,30): «quod nos clementiae nostrae solita provisione comprimimus, ne paulatim sinendo, graviorem vindicare coganur offensam; benigni quippe principis est non tam delicta velle punire, quam tollere: ne aut acriter vindicando, aestimetur nimius, aut Jeviter agendo putetur improvidus» (carta al Senado romano, ẫo 507-511). 
luego que recurrir al peso de la ley; debe ser vigilante para evitar que, por su descuido, el delito adquiera tales proporciones que sea necesario un castigo más duro y pueda reprochársele así que ha sido excesivo en la sanción o que fue negligente y poco previsor, cuando todavía era posible evitarla. Esta clemencia del príncipe en prevenir puede extenderse también a perdonar y en ningún caso perjudica a los derechos públicos, porque la piedad y la clemencia del gobernante no contradicen a la justicia y la equidad, sino que las superan ${ }^{68}$.

6.- Un factor decisivo para moralizar la vida pública y mantener la paz interior y el bienestar del reino era combatir la rapiña y la depredación, que también practicaban los ostrogodos de Teodorico, aunque quizá en menor medida que en otras partes. La ocupación violenta de tierras de los vencidos, el expolio de sus bienes y tesoros no habían escaseado y esto era una fuente permanente de inseguridad y conflictos. Con ser ya mucho, no bastaba aquí disponer de una buena legislación y aplicarla correctamente: había que dar además una solución estable y pacífica al asentamiento de los vencedores, sin dejarlo exclusivamente al arbitrio de la ocupación de hecho y por fuerza o a los simples derechos de conquista. Para ello Casiodoro propone dos medidas generales: organizar el fisco para que el aparato público pudiera disponer de los recursos necesarios sin recurrir a la depredación o la violencia; y perseguir el fraude o la extorsión en las relaciones de los súbditos, porque «es un crimen buscar el oro por medio de la guerra, mientras que es lícita la riqueza por la que nadie es perjudicado y sólo se adquiere bien lo que no se quita a sus dueños legítimos ${ }^{69}$. Como se ha dicho más arriba, los pueblos bárbaros no disponían de un sistema fiscal organizado, pero en algunos casos se sirvieron de lo que quedaba del romano y Casiodoro quiso mantener en el reino ostrogodo «el beneficio legal del fisco", (legale compendium fisci), al que ya venían tributando los súbditos romanos cuando Teodorico se asentó en Italia. Con ello se evitarían según pensaba- las rapiñas del poder, al tener éste cubiertas sus necesidades con los bienes allegados por una recaudación justa y regulada por la ley. Pero esto suponía, ante todo, que los diversos cargos públicos, empezando por el

68 Ibid., II,30 (MGH XU,63): «non praejudicat juri publico personalis exceptio, quia beneficialem esse principem licet, nec intra regulas constitui potest munificentia regalis arctari; ira levia coerceatur gravissimis institutis, impatiens ambitio jure refrenetur: clementia non habet legem» (carta al Prefecto pret. Fausto, año 507-511); ibid., H,9 (MGH XII,51): «inclinari precibus nostra novit humanitas, nec pro affectu pietatis fines potest iustitiae custodire; benigni quippe principis est, ad clementiae commodum transilire terminos aequitatum: quando solo est misericordia, cui omnes virtutes cedere honorabiliter non recusant» (carta al Prefecto pret. Fausto, año 507-511).

69 lbid, LX,3 (MGH XII,270): «aurum siquidem per bella quarere nefas est...; honesta vero sunt lucra per quae nemo laeditur, et bene adquiritur quod a nullis adhuc dominis abrogaturs (carta a Bergantino, conde del Patrimonio, año c. 527). Todavía en esos años seguía practicándose la rapiña por parte de los poderes públicos. Además de rechazarla, Casiodoro propone que se busque y exploten yacimientos de metales preciosos, pero que no se expolie a los ciudadanos.

Proyección internacional de la jglesia hispana Hispania Sacra 51 (1999) 
rey, se contentasen con percibir lo que les correspondía en derecho para no vivir, de un lado, en una estrechez que estimulase su codicia, pero renunciando también, de otro, a enriquecerse ilícita y abusivamente sirviéndose de su poder ${ }^{70}$.

Suponía igualmente que las futuras cargas del fisco debían pesar también sobre los godos y no sólo sobre los romanos; y que el reparto de bienes (usurpados muchos de ellos con la invasión) entre unos y otros debía hacerse de modo legal y justo, para poder elaborar así un censo tributario claro, eficaz y estable, lejos de los agravios que harían difícil, cuando no imposible, la convivencia entre ambos pueblos. Para llevarlo a cabo se recurrió al régimen de la hospitalitas, que ya se venía practicando en el Imperio desde hacía tiempo. Había sido regulado con gran precisión por los emperadores Arcadio y Honorio, en el año 398, para establecer y «aposentar» tropas fijas en las fronteras y esa misma función tenía todavía en el siglo VI para Justiniano ${ }^{71}$; Casiodoro lo pensó, sin embargo, como el medio de establecer definitivamente a los godos en su nuevo reino italiano. El régimen de hospitalitas establecía que el dueño de la propiedad (en este caso el romano) se quedase con las dos terceras partes de ella y cediese el tercio restante al «huesped» godo (consors); hechos los lotes, el dueño elegía en primer lugar un tercio, luego elegía el suyo el huésped y el tercio restante pasaba automáticamente al dueño ${ }^{72}$. Sin embargo, en los reinos bárbaros que intentaron establecerse en territorio romano sustituyendo al Imperio (Ataúlfo) o imitándolo (Teodorico), dicho régimen se aplicó interpretando la ley del modo más favorable a los godos, a quienes correspondieron

70 lbid., IX,3 (MGH XII,24); «fisci volumus legale custodire compendium: quia nostra clementia rebus propriis videtur esse contenta; et sicut nullum gravare cupimus, ita debita nobis perdere non debemus; indigentian iuste fuginus, quae suadet excessus; dum pernitiosa res est in imperante tenuitas; modus ubique laudandus est» (carta a los senadores Saturnino y Umbisto, año 507-511). Evitar excesos (en este caso la miseria o la codicia) es una máxima frecuente en Casiodoro, siguiendo la tradición clásica transmitida por Cicerón y otros: «ratio iubet, ne quid nimis, sed omnis cum moderamine fiant» o fórmulas similares (De Orat., De Senect., De Offic.; Colum. II; etc.).

71 La ley del año 398 se encuentra en el Cod. Theodor. 7,8,5 y en el Cod. Iust. 12,40,2; el texto latino, con traducción castellana, puede verse también en A. GarCIA Gallo, Manual de Historia del Derecho Espaniol (Madrid 19673) II,262-263. Sobre las reformas hechas por Justiniano y sus diversas aplicaciones cfr. L. BRÉHIER, Las instituciones del Imperio Bizantino, trad. esp. de J. Almoina (C. de México 1956) pp. 302 ss. y A. GUllLoN, La civilisation byzantine (Paris 1974) passim. La ley de Arcadio y Honorio establecía ya la salvedad de que «tratándose de varones ilustres» se les entregase no la tercera parte, sino la mitad de los bienes; los godos, considerándose los nuevos «señores», trataron quizá de acogerse a esta claúsula y aun ampliarla.

72 Cod. Theodos 7,8,5: «,..para quitar toda iniquidad tanto de los medidores como de los huéspedes, el dueño posea sin miedo y con seguridad dos partes de su propia casa y se entregue la tercera al huésped; de este modo, que dividida en tres partes la casa, el duefío tenga la facultad de elegir la primera, el huésped elija la segunda, la que quiera, y la tercera quede al dueño. Pues es en todo conforme a la equidad y a la justicia que quien la disfruta por sucesión o la goza por compra o edificación, tenga en primer término la cosa elegida a su juicio y la dejada» (trad. de A. García Gallo, loc. cit.). 
dos tercios de las propiedades romanas ${ }^{73}$. Esto equivalía, en realidad, a una especie de expropiación forzosa, en aras del bien común de la convivencia; pero acarre 6 frecuentes conflictos: por parte de los romanos porque se resistían a ceder de grado la mayor porción de sus bienes; por parte de los godos porque muchos de ellos se negaban a devolver lo usurpado o aspiraban a hacerse dueños de todo, como vencedores ${ }^{74}$.

Implantado en sus líneas fundamentales, el fisco del nuevo reino, para no ser opresivo, debía ser como el resto del ordenamiento político-social: justo, equitativo y clemente. Ante todo justo, «puesto que en todos los asuntos queremos -dice Teodorico- que se respete la justicia, pero más todavía en aquéllos que se presentan en nombre de nuestro fiscos ${ }^{75}$. Un fisco justo supone para Casiodoro varias cosas: no gravar con nuevos impuestos a una población todavía maltrecha, sino mantener los ya establecidos y aceptados, pero gestionándolos mejor para evitar la sangría de una mala administración recaudatoria, pues sólo así el tesoro público verá incrementar sus ingresos sin que los súbditos vean aumentar sus tributos ${ }^{76}$; y si hay que imponer alguno nuevo, éste deberá ser igualmente justo o el buen gobernante renunciará a él, pues es más

73 Así habría sucedido tras la ocupación de la Aquitania y la Novempopulonia por Ataúlfo (410411) y de parte de Italia por Teodorico (cfr. A. D'ORS, El Código de Eurico, Roma-Madrid 1960, pp. 173-74). También se habrían quedado con los dos tercios los visigodos establecidos en España; cfr. A. GarCIa Gallo, «Notas sobre el reparto de tierras entre visigodos», Hispania, 1(1941) 40-63; E.A. THOMPSON, Los godos en España (Madrid 1971) p. 156. No todos los historiadores están de acuerdo en que los visigodos aplicasen así la hospitalitas (cfr. J. ORLANDis, «El reino visigodo, siglos VI y VII», en Historia Económica y Social de España, dir. V. Vázquez de Prada, Madrid 1973, II,544-55); pero el Código de Leovigildo contiene nonmas que se refieren a los dos tercios de los godos y el tercio de los romanos (cfr. A. GARCIA GaLLo, loc.cit.) y también el Liber Judicionum en su versión romanceada (Fuero Juzgo) alude a esa proporción (cfr. A. GARCla GALLO, o.c., II,364-65).

74 El propio Casiodoro propone como ejemplo a imitar en esa delicada tarea del reparto a Liberio, que habría logrado acuerdos aceptables por todos: «in tertiarum deputatione Gothorum Romanorumque et possessiones iunxit et animos; nam cum se homines soleant de vicinitate collidere, istis praediorum communio causam videtur praestitisse concordiae: sic enim contigit ut utraque natio, dum communiter vivit, ad unum velle convenerit..., una lex illos et aequabilis disciplina complectitur» (CAS., Var. II,16; MGH XII, 55-56; carta al Senado romano, año 507-511). Las reclamaciones de romanos huidos que habian sido expoliados debieron ser frecuentes (cfr. ibid. II,18).

75 CAS., Var. IV,32 (MGH XX,128): «cum in omnibus causis velimus iustitiam custodiri, quia regni decus est aequitatis affectus, in eis maxime quae fisci nostri nomine proponuntur nequaquam detestabilis calumnia in invidiam regnantes affligat» (carta al sajón Duda, año 507-511).

76 Ibid., II, 16 (MGH XII,55); «censum non addendo, sed conservando protendens (Liberio); dum illa quae consueverant male dispergi, bene industria providentiae collegit; sensimus auctas illationes, vos addita tributa nescitis» (carta al Senado romano, año 507-511). Teodorico-Casiodoro proponen al Senado cómo quieren organizar el fisco del reino, siguiendo el modelo de lo hecho por el patricio Liberio, siendo prefecto del Pretorio. Casiodoro da por supuesto aquí que la fiscalidad del Bajo Imperio no era opresiva para la ciudadanos; pero de creer a Orosio, muchos de ellos, y especialmente los provinciales, se sentían abrumados por excesivos impuestos.

Proyección internacional de la iglesia hispana Hispania Sacra $51(1999)$ 
digno de alabanza que pierda el fisco lo que se intenta recaudar injustamente ${ }^{77}$. Por ello, el propio rey debe frenar la voracidad y el excesivo celo de los recaudadores que, pensando que así ganarán su aprobación y recompensa, intentan obtener lo más posible para las arcas regias por cualquier medio abusivo o de fuerza: «no indaguemos -dice al senador Marcelo al encomendarle el fiscocuántas veces nades en la riqueza, sino de qué manera lo logres; esfuérzate por ser equitativo, si quieres agradarme: no busques obtener recompensas de mi poder, sino más bien de la justicias ${ }^{78}$.

Ser equitativo en cuestiones fiscales consiste en que todos paguen según les corresponde; en que los económicamente débiles no sean gravados más allá de sus posibilidades ni los acaudalados se eximan de tributos amparándose en su poder; en que no se abrume a los inocentes con una falsa imputación de deudas ni se exonere a quienes se niegan a pagar lo que se les reclama en justicia, «porque considero -añade- verdadera ganancia sólo lo que obtengo con la aprobación de la honradez» ${ }^{79}$. Pero en estas cuestiones, quizá más que en otras, tampoco basta con ser justo y equitativo en la distribución y exigencia de impuestos, porque no todo depende de la voluntad del ciudadano: hay también imprevistos, suceden calamidades naturales o familiares, se pierden cosechas, desaparecen quienes llevaban el peso del comercio o los cultivos, no llegan los beneficios previstos y no siempre disponen las gentes de recursos para afrontar el pago de tributos sin quedarse en la miseria. Entonces el buen gobernante debe recurrir nuevamente a la clemencia y la piedad, aplazando pagos, condonando deudas o incluso auxiliando a los necesitados con los recursos de las propias arcas regias, para que puedan tener «un respiro» (aliquatenus respirent) hasta rehacerse, «porque es propio de un príncipe providente socorrer a

77 Ibid., I,22 (MGH XII,26): «quandiu laudabilius a parte fisci perditur cum iustitia non habetur» (carta a Marcelo, abogado del físco, año 507-511); cfr. IV,34 (MGH XII,129): «nolumus lucra quaeri quae per funesta possunt scelera reperiri» (carta al sajón Duda, año 507-511); ibid., П,38 (MGH $\mathrm{XII}, 67$ ): «opes nostras cupimus thesauro pietatis augeri: execrantes commoda, quae nobis vexatorum fuerint calamitatibus acquisita» (carta al Procurador Fausto, affo 507-511).

$\tau_{B}$ Ibid., (MGH XII,26): «non ergo quoties superes, sed quemadmodum vincas inquiramus (Teodorico); aequitatem nobis placiturus intende: non quaeras de potestate nostra, sed potius de iure victorias».

79 Ibid.: «ita ergo per medium iustitiae tramitem moderatus incede: ut nec calumnia innocentes graves, nec iustis petitionibus retentatores exoneres; illa enim vera lucra judicamus, quae integritate suffragante percipimus»; ibid. II,23 (MGH XI,59): «fiet enim ut exactorum nimietas, dum a potentibus contennitur, in tenues conversa grassetur» (carta al Senado romano, año 507-511); ibid., II,25 (MGH XII,60): «detestamur enim miseros premi..., cunctorum nos respiciunt laesiones...; nuper itaque provincialium judicum relatione comperimus domos aliquas prepotentitum suas non implere per ordinem functiones; hinc fieri ut dum illationis quantitas procurare quaeritur, a tenuibus summa potior exigatur» (edicto, año 507-511). El abuso de los recaudadores, que exprimían a los menos favorecidos para cubrir lo que dejaban de pagar los poderosos debió estar suficientemente extendido como para exigir un edicto. En el Codex Justiniani la palabra «functio» tenía el sentido técnico de pago de impuestos. 
los que están agotados por la miseria y los sufrimientos, para que la indulgencia de los mandatos mitigue la dureza de las desgracias» ${ }^{80}$.

Si la codicia y la rapiña de los poderes públicos pueden quizá erradicarse con un fisco justo, equitativo y clemente, las de los ciudadanos exigen otras medidas para ser frenadas: eliminar, o al menos perseguir, el fraude y la especulación en las relaciones comerciales. Es bueno que los mercaderes hagan negocio o no existiría un comercio beneficioso para la sociedad; es bueno que compren lejos y vendan cerca para obtener beneficios razonables por su esfuerzo y riesgo; pero el buen gobernante debe garantizar que todos los ciudadanos tengan constancia de los pesos y medidas fiables, «porque todo se perturba si se mezcla la honradez con los fraudes ${ }^{81}$. Por otro lado, también es bueno que los agricultores vendan sus excedentes y que los comerciantes los compren para negociar con ellos; pero que no intenten aprovecharse de la necesidad de las gentes para adquirir sus cosechas, acaparando los productos y vendiéndoselos luego a precios más elevados, «porque es más justo que las cosechas de la tierra aprovechen ante todo a quienes la cultivan y no a la codicia de mercaderes extraños ${ }^{82}$. En todo caso, el nuevo orden de justicia que se quiere instaurar en el reino excluye que nadie, menospreciando a los demás, los aplaste con cargas excesivas ${ }^{83}$.

Todas las medidas apuntadas para mantener el reino en paz y prosperidad serían prácticamente estériles, si no fueran puestas en práctica por buenos gobernantes y hombres públicos; pueden existir leyes excelentes, normas de convivencia objetivamente adecuadas e irreprochables: de poco o nada servirán, si no son cumplidas ni hechas cumplir por quienes tienen el poder para ello. Éstos deben ser intachables «porque sólo puede regir correctamente a otros quien se ha aplicado a comportarse decentemente»; es decir, «a huir de la avaricia, a

80 Ibid., IV,19 (MGH XII,122): «decet principalem providentiam fessa refovere, ut asperitatem casuum mitiget lenitas jussionum» (carta al senador Gemello, año 507-511). En esa misma carta se condonan los impuestos del trigo, el vino y el aceite a varias provincias golpeadas por desgracias, «ut haec remissio solutionis copiam possit praestare provinciis, et respirent aliquatenus fessi praesenti salubritate decreti».

81 Ibid., I,10 (MGH XII,19): «exerceantur negotiatores in mercibus; emantur late, quae vendantur angustius; constet populis pondus ac mensura probabilis, quia cuncta turbantur, si integritas cum fraudibus misceatur» (carta a Boecio, año 507-511).

82 Ibid., I,34 (MGH XII,33): «copia frumentorum provinciae debet primum prodesse cui nascitur: quia justius est ut incolis propria fecunditas serviat, quam peregrinis commerciis studiosae cupiditatis exhauriat» (carta a Fausto, Prefecto pret., año 507-511).

83 Ibid., II, 13 (MGH, XII,52-53); «quod nostri temporis manifestum est non decere justitian, ut aletrius despectus alterum gravet» (carta al sajón Frumarith, año 507-511).

Proyección internacional de la iglesia hispana Hispania Sacra 51 (1999) 
buscar lo que es justo, a amar la moderación y a despreciar la ira» ${ }^{84}$. Y esto, empezando por el propio rey, que es como un espejo donde se mira el pueblo para bien o para mal, imitando sus vicios o virtudes, «pues el alma del rey dice- es la madre de la decencia pública y según sean las decisiones del gobernante así será también la forma visible de la libertad; es ciertamente más fácil que se equivoque la naturaleza, si se me permite hablar así, que el príncipe pueda configurar un Estado que no sea semejante a sí mismo»"85. Por extensión, todos los cargos públicos deben tener también una conducta intachable y aparecer así ante los demás, porque lo que la gente dice de ellos se aplica a las instituciones del reino ${ }^{86}$; un mal juez, un mal recaudador del fisco, un mal senador, un mal gobernador de provincias no sólo acarrean su propio desprestigio, sino el de los cargos y organismos que representan. Dos cosas especialmente deben cuidar los hombres públicos: no transgredir la ley, ni siquiera en cosas pequeñas que suelen llevar a otras mayores; y no admitir en su entomo ni fomentar el trato con personas que, como auténticos delincuentes, menosprecian la ley y pretenden sólo ampararse subrepticiamente en la familiaridad con los gobernantes para servirse de ella y cometer sus desmanes ${ }^{87}$. Por ello el rey debe poner el máximo cuidado en elegir hombres tales que puedan dar claros ejemplos para las gentes sencillas ${ }^{88}$.

A grandes rasgos, el intento de Casiodoro-Teodorico es, pues, el siguiente: establecer un reino «donde no haya lugar para la violencia ni haya que temer los males de la avaricia»; que esté bien «defendido por las armas y ordenado por las leyes»; donde todos se esfuercen de grado «en colaborar a lo que se ve que es de utilidad pública;» donde el propio gobemante «crea oportuno elegir aquello que es digno de la aprobación de todos»; donde «a todos los pueblos se

84 Ibid., III,13 (MGH XX,86): «is potest alios bene regere, qui se studuit sub decore tractare» (carta al senador Sunhivado, año 507-511); ibid., III,11 (MGH XII, 85): «avara fuge, justa sequere, modesta dilige, iracunda contemne» (carta a Argolino, Prefecto de Roma, año 510-511).

85 lbid. III,12 (MGH XII,85-86); «publici enim decoris mater est mens regentis, et quale fuerit dominartis arbitrium, talem parit libertatis aspectum; facilius est quippe, si dicere fas est, errare naturam, quam dissimilem sui princeps possit formare rempublicam» (carta al Senado romano, año 510-511).

86 Ibid., (MGH XII, 86); «quia quidquid de vobis fama loquitur, nostris institutionibus applicatur».

87 Ibid., II,12 (MGH, XII, 52): «cavete itaque ne culpis quamvis parva praebeatur occasio, scientes periculum gravissimum fore, si studeatis vel leviter injusta committere; in qualitate est, non in quantitate peccatum; mensuram siquidem non quaerit injuria; imperium, si parvo contemnitur, in omni parte violatur» (carta al conde de los Siliquatarios, año 507-511); ibid., I,30 (MGH XII,31): «intersit igitur inter splendorem vestrum moresque mediocres: refugite tales familiares, qui sint injuriarum ministri: qui honori vestro nitantur adscribere, quod delinquunt, et dum levitates suas asserere (exercere) cupiunt, vestram reverentiam implicare contendunt» (carta al Senado romano, año 507-511).

88 Ibid., I,23 (MGH XII, 27): «debet enim de talibus viris esse cura praecipua, qui dare possunt minoribus evidenter examplas (carta a los patricios Celino y Agapito al ser nombrados jueces extraordinarios, año 507-511). 
les aplique la misma justicia» y los súbditos estén seguros «porque viven bajo la equidad de los gobernantes»; donde éstos «protejan a todos en su conjunto, pero más si cabe a los más desamparados»; donde los hombres públicos «muestren conductas acordes con el honor de sus cargos»; donde la vida de los ciudadanos «no peligre por el capricho de cualquier hombre armado ni sus bienes por un fisco rapaz»; donde «en todas partes se conviva de modo civilizado y moderado»; donde «el bien común sea fomentado por buenos hombres públicos» ${ }^{89}$. Sólo así, por lo demás, el reino de Teodorico podrá ser modelo a imitar por otros pueblos, que podrán ver en él el ejemplo de la «justicia goda» ${ }^{90}$.

No es Casiodoro aficionado a hacer síntesis de sus ideas, sino a dejarlas como ya he dicho- dispersas en sus escritos, para aplicarlas según las necesidades y conveniencias de cada caso; pero si hubiese que elegir un pasaje donde haya reunido algunas de las principales directrices de su proyecto de transformación de los pueblos bárbaros en reinos organizados bajo el imperio de la ley y donde la vida pública esté sujeta a normas que hagan posible la convivencia pacífica y segura, garantizando vidas y haciendas, éste es seguramente la carta dirigida a todos los provinciales de las Galias, anunciándoles la llegada de Gemello para gobernarlos. El texto es suficientemente elocuente: «revestíos dice- de costumbres romanas; despojáos de la barbarie, desechad la crueldad de las mentes, porque no conviene que viváis con costumbres ajenas bajo la justicia de nuestro reinado...; acoged progresivamente las costumbres acreditadas; no os sea tarea enojosa la novedad que es buena; ¿qué puede haber más dichoso que el que los hombres confíen sólo en las leyes y no teman las cosas dejadas al azar?; los derechos públicos bien establecidos son las ayudas más seguras de la vida, protección de los débiles y freno de los poderosos; amad aquello de donde procede la seguridad y progresa la conciencia, porque los bárbaros viven según sus apetencias (ad libitum) y allí encuentra más fácilmente la muerte propia quien puede tener algo que guste (a otro); sacad a la luz los bienes escondidos en un largo asedio, porque es tanto más noble aquél que más brilla con buenas costumbres y bienes abundantes; comprended que no hay que preferir a los hombres por su vigor corporal, sino por su inteligencia, y que con razon son encumbrados quienes pueden hacer a los otros el servicio de lo que es justo» ${ }^{91}$.

89 lbid., IV,9; IV,12; II,20; I,12; I,9 (2); I,8; I,11; XI,8; III,34; III,38.

90 $\mathrm{lbid}$., III,23 (MGH XII, 91) «aequitati fave, innocentiam animi virtute defende; ut inter nationum consuetudinem perversam, Gothorum possis demonstrare justitjam: qui sic semper fuerunt in laudis medio constituti, ut et Romanorum prudentiam caperent, virtutem gentium possiderent" (carta al conde Colosseo, gobernador de Pannonia Simense, año 507-511). Sobre la «justicia goda» habla Procopio en su De bello Gothorum.

91 lbid., III,17 (MGH XII,88): «vestimini moribus togatis; exuite barbariem, abjicite mentium crudelitatem, quia sub aequitate nostri temporis non vos decet vivere moribus alienis...; recipite pau-

Proyección internacional de la iglesia hispana Hispania Sacra 51 (1999) 
El proyecto de Casiodoro era, sin duda, una utopía y de hecho acabó fracasando, aunque por otras razones también de orden político; pero no era una utopía sin visos de realismo: suponía una novedad para los pueblos bárbaros, pero no era una novedad completamente ajena a lo que ya muchos ciudadanos habían conocido como forma de vida con buenos resultados, porque como el mismo Casiodoro dice, «queremos que viváis como véis que prosperaron nuestros antepasados ${ }^{92}$. En un siguiente artículo intentaré explicar el proyecto elaborado en otros reinos bárbaros, especialmente el de los suevos de España y el de los vándalos de Africa. Ambos se encontraron en situaciones en parte similares y en parte distintas; en ambos también las propuestas fueron diversas.

latim veridicos mores; non sit novitas molesta, quae proba est; quid enim potest esse felicius quam homines de solis legibus confidere, et casus reliquos non timere?; jura publica certissima sunt humanae vitae solatia, infirmorum auxilia, potentum frena; amate unde securitas venit, et conscientia proficit; gentilitas enim vivit ad libitum: ubi magis reperit mortem propriam qui potest habere quod placeat; vos jam securi ostentate divitias parentum; bona longo situ recondita prodantur in lucem; quia tantum quis nobilior est quantum et moribus probis et Juculenta facultate reluxerit...; intelligite homines non tam corporea vi quam ratione praeferri, et illos merito crescere qui possunt aliis iusta praestare» (carta a todos los provinciales de las Galias, año 508).

92 Ibid., III,24 (MGH XII,92): «sic vos volumus vivere, quemadmodum parentes nostros... cemitis flonuisse» (carta a todos los bárbaros y romanos de Pannonia, año 507-511). 